\title{
Precipitation forecasting by a mesoscale numerical weather prediction (NWP) model: eight years of experience
}

\author{
P. Kaufmann, F. Schubiger and P. Binder
}

MeteoSwiss, P.O. Box 514, Zurich, CH-8044, Switzerland

E-mail for corresponding author: pirmin.kaufmann@meteoswiss.ch

\begin{abstract}
The Swiss Model, a hydrostatic numerical weather prediction model, has been used at MeteoSwiss for operational forecasting at the mesobeta scale (mesh-size $14 \mathrm{~km}$ ) from 1994 until 2001. The quality of the quantitative precipitation forecasts is evaluated for the eight years of operation. The seasonal precipitation over Switzerland and its dependence on altitude is examined for both model forecasts and observations in the Swiss rain gauge network sampling daily precipitation at over 400 stations. The mean diurnal cycle of precipitation verifies the model against the automatic surface observation network on the basis of hourly recordings. In winter, there is no diurnal forcing of precipitation and the modelled precipitation agrees with the observed values. In summer, the convection in the model starts too early, overestimates the amount of precipitation and is too short-lived. Skill scores calculated for six-hourly precipitation sums show a constant level of performance over the model life cycle. Dry and wet seasons influence the model performance more than the model changes during its operational period. The comprehensive verification of the model precipitation is complemented by the discussion of a number of heavy rain events investigated during the RAPHAEL project. The sensitivities to a number of model components are illustrated, namely the driving boundary fields, the internal partitioning of parameterised and grid-scale precipitation, the advection scheme and the vertical resolution. While a small impact of the advection scheme had to be expected, the increasing overprediction of rain with increasing vertical resolution in the RAPHAEL case studies was larger than previously thought. Frequent updating of the boundary conditions enhances the positioning of the rain in the model.
\end{abstract}

Key words: numerical weather prediction, quantitative precipitation forecast, model verification

\section{Introduction}

Precipitating weather systems, in conjunction with their sometimes devastating accompanying phenomena such as gales, hail and flooding, have an immediate human impact and influence a broad range of activities, e.g. agriculture, construction and traffic. Therefore, precipitation, its timing (onset and duration), location and intensity, is certainly a key parameter in weather prediction and has significance for operational hydrology. Precipitation is highly variable in space and time and is strongly influenced by orographic forcing. Thus, reasonable precipitation forecasts require a numerical weather prediction model of high horizontal resolution, especially in mountainous regions.

For the verification of the precipitation forecast of such high-resolution models, a dense network of rain gauges is needed. Such dense networks of precipitation measurements are not generally available but, in Switzerland, an operational network of automated stations is available. The hourly precipitation totals of these stations were used to assess the performance of the precipitation forecast of the operational weather prediction model, the Swiss Model (SM). A second, spatially denser, network of rain gauges provided values of daily accumulated precipitation. The routine verification started with the SM becoming operational in 1994 and was continued until the phase-out in 2001 when the successor weather prediction model, the Alpine Model (aLMo), became operational. The seasonal verification of daily totals was extended back to summer 1993 so that for each season, eight years of verification results are available.

One of the goals of the Mesoscale Alpine Programme (MAP) (Bougeault et al., 2001), a multi-year, international initiative to advance knowledge in mountain meteorology, was to collect meteorological data with high spatial and temporal density for limited time periods to advance model 
development. The comparison of the precipitation forecast of different numerical weather prediction models with an emphasis on flood events was the main objective of the project HERA (heavy precipitation in Alpine regions) (Volkert, 2000). The SM presented here was one of the four operational models tested within HERA by Mladek et al. (2000) and rated well in the comparison.

The RAPHAEL project takes one more step towards the vision of integrating forecast precipitation data into flood warning systems (Volkert, 2000) by comparing the runoff prediction that the hydrological models derived from numerical weather prediction output. The SM was again one of the models used in the RAPHAEL study and four cases from the RAPHAEL project are presented here.

The general experience with the quantitative precipitation forecast by very high-resolution NWP models shows that increasing horizontal resolution on one hand increases the realism of the precipitation fields but on the other hand often fails to increase the verification scores due to insufficient observational resolution and the limited predictability of the exact location of small scale features (Stein et al., 2000; Mass et al., 2002). The resolution of the SM used here, however, is coarse enough so that it should not be affected by this limitation.

The problem of the inadequate availability of highresolution data was overcome within RAPHAEL through a common effort to combine many - usually inaccessible data sources into a dense network of rain measurements. This was only possible for a few heavy precipitation episodes of several days each.

The weather prediction model and its main features are described next, followed by the verification strategy, before discussion of the daily cycles, seasonal totals and seasonal scores. Case studies are presented to show the model performance for a few selected heavy-precipitation events that were investigated during the RAPHAEL project. Finally, some information is provided on the new non-hydrostatic model now used operationally in the COSMO consortium (http://www.cosmo-model.org or mirror at http://cosmomodel.cscs.ch) in Germany, Greece, Italy, Poland, and Switzerland.

\section{The weather prediction model}

The Swiss Model (SM) was the operational numerical weather prediction model from 1994 to 2001 for short-range numerical weather prediction (NWP) at MeteoSwiss. In a slightly different configuration, the same model was operational at the DWD (German Weather Service) until the end of 1999 under the name Deutschland Modell (DM). It is derived from the Europa Modell (EM) of the DWD and has been developed in close collaboration between MeteoSwiss and DWD. A description of the EM is given in Majewski (1991). It is a hydrostatic meso- $\alpha$-scale model based on the primitive equations. The full physical parameterisation package includes vertical turbulent transport, convective and grid-scale precipitation with cloud microphysics, radiation and a detailed treatment of the soil and surface-atmosphere exchange processes.

The operational SM had a resolution of $145 \times 145$ grid points horizontally and originally 20 vertical layers (later 31 layers). The vertical layers were in hybrid coordinates (pressure levels - terrain following). It used a rotated longitude/latitude grid with a resolution of 0.125 degrees (c. $14 \mathrm{~km}$ ) centred over Switzerland (Fig. 1). The origin of the rotated coordinate system was at $10^{\circ} \mathrm{E} / 50^{\circ} \mathrm{N}$ to minimise the distortion of the grid over Europe. The full domain of the Swiss Model is shown in Fig. 1.

Because enthalpy and total water content are the prognostic variables of the model, the condensation rate of water vapour to cloud water does not appear explicitly in the scheme. Condensation and evaporation of cloud water is treated implicitly by diagnosing temperature, water vapour and cloud water from enthalpy and total water by use of the water vapour saturation criterion.

A regular schedule of two daily operations at 00 UTC and 12 UTC started on 25 March 1993, becoming officially the operational model in spring 1994. It used a semiLagrangian advection scheme with a 240 seconds time step. Starting on 25 September 199512 UTC, the forecast range was extended from 36 hours to 48 hours. The only other major change in the operational setup was introduced with the 7 September 199912 UTC run by increasing the vertical resolution from 20 to 31 levels for the purpose of MAP (Bougeault, 2001). At the same time, the advection scheme was switched from a semi-Lagrangian to an Eulerian scheme with a 60 seconds time step. The relaxation towards the driving model at the top of the model domain was replaced by a radiative upper boundary condition. This configuration was in place until 31 July 2001, when the SM finally ceased operations after it had already been replaced a few months earlier by the Local Model as operational model.

\section{PRECIPITATION PARAMETERISATION}

NWP models resolve those meteorological processes that can be represented explicitly by the computational grid. However, sub-grid scale phenomena always exist and, as these cannot be represented directly on the grid, the bulk effects of these sub-grid-scale processes on the larger-scale fields must be taken into account for correct simulation of the overall atmospheric development in the model. This is 


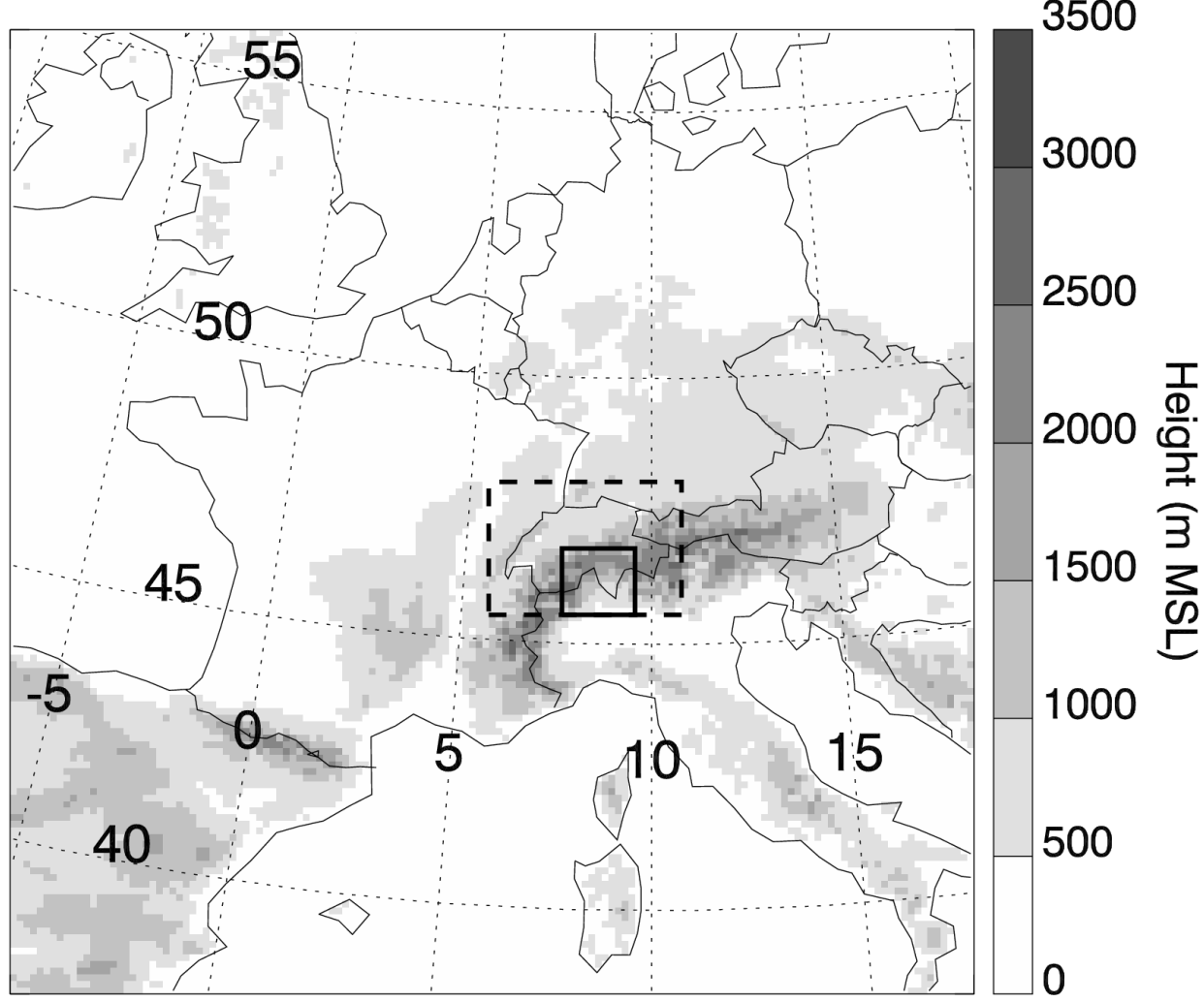

Fig. 1. Swiss Model topographic heights with $14 \mathrm{~km}$ resolution. The dashed frame is enlarged in Fig. 3 and contains the area covered by the long term operational verification. The solid frame is the Ticino-Toce area containing the Ticino at Miorina catchment area of the RAPHAEL case studies.

done through parameterisation schemes.

The precipitation is partitioned into two fractions: one part is the grid-scale precipitation that occurs upon saturation of the air within the model grid elements and thus is often referred to as 'explicit condensation' and is loosely related to the more physical term of 'stable' or 'stratiform' precipitation. The other fraction is the parameterised precipitation, which is devised to capture the sub-grid scale cumulus convection. As the mesh size decreases, an increasing fraction of the circulation features connected to convective systems will be resolved at the grid scale. The partitioning into the components depends on the mesh size. It is an open question at which grid size the convection is fully resolved on the model grid and the parameterisation of moist deep convection can be omitted. Stein et al. (2000), for example, found $2.5 \mathrm{~km}$ to be probably still a bit too coarse to fully resolve the convection.

Convective parameterisation is applied at conditionally unstable grid points, explicit condensation at saturated grid points. A danger for the meso- $\beta$-scale models is the possibility that conditional instability occurs at saturated grid points and therefore convective clouds develop directly on the grid-scale (grid-point storms), over-predicting the convective activity due to the mesh size being much larger than the actual convection.

The grid scale precipitation in the SM is parameterised with a Kessler-type microphysics scheme, including an icephase. The cumulus convection is modelled with a mass flux scheme. These precipitation parameterisations are briefly introduced in the following.

\section{Grid-scale precipitation}

A detailed account of the grid scale precipitation scheme of the SM is given in Müller et al. (1987) and part of the following description is taken from that source. The parameterisation of the cloud microphysics accentuates the role of the ice phase for precipitation formation by emphasizing the Bergeron-Findeisen process. The parameterisation scheme is of the Kessler type and allows for interactions between water vapour, cloud water, rain and ice (Fig. 2); it includes autoconversion of cloud water to rain and to ice, the latter here called nucleation, accretion, riming, shedding, melting, deposition and evaporation of raindrops.

Autoconversion and nucleation are the processes initiating precipitation formation. The remaining conversion rates can 


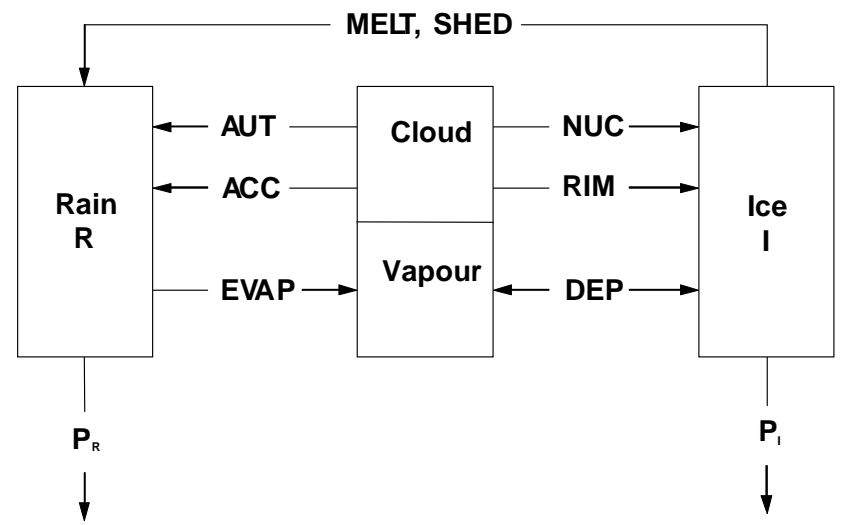

Fig. 2. Schematic diagram of parameterised cloud microphysics: Processes involved in rain $\left(P_{R}\right)$ and snow $\left(P_{P}\right)$ formation are autoconversion of cloud water to rain (AUT), nucleation (NUC), accretion (ACC), riming (RIM), shedding (SHED), melting (MELT), deposition (DEP), and evaporation of raindrops (EVAP) (after Müller et al., 1987).

only become non-zero if precipitation falls into the layer under consideration.

\section{Convective precipitation}

The cumulus parameterisation scheme used in the SM (Tiedtke, 1989) can be grouped into the family of Mass flux schemes. Other representatives of this type of parameterisation are described by Arakawa and Schubert (1974), Emanuel (1991), Grell (1993), and Emanuel and Zivkovic-Rothman (1999).

The Tiedtke (1989) scheme used in the SM closes its bulk cumulus ensemble model, represented by a 1-dimensional cloud model, by making convection dependent on the moisture supply by large-scale flow convergence and boundary layer turbulence. In mass-flux schemes the effects of the clouds on the resolvable-scale variables are parameterised in terms of the convective mass fluxes and convection is assumed to influence the environment through environmental subsidence and detrainment at the top of the updraft or the bottom of the downdraft.

\section{Verification strategy}

\section{GENERAL}

The operational SM was verified routinely with surface observations from Switzerland. The focus on Switzerland was partly due to the fact that MeteoSwiss, as a national weather service, has a primary interest in the quality of the national weather predictions and, partly, it was due to the fact that national observational data of a dense rain-gauge network were readily available, whereas it is still a major venture to collect European high-resolution precipitation data for more than just short periods or small areas.

In the routine verification of the SM, hourly values of four near-surface weather elements, namely $2 \mathrm{~m}$-temperature and dew point, $10 \mathrm{~m}$-wind, total precipitation and cloud cover, were verified with observations of the automatic network of MeteoSwiss (ANETZ). The verification of the precipitation will be presented in the next section. A spatially denser network of daily rain-gauge observations is used for the verification of seasonal precipitation totals.

The correspondence between the SM grid points and the observations depends on the height difference between the observation site and the model surface at the nearest four surrounding grid points:

- The nearest grid point is chosen if the absolute value of the height difference is less than $100 \mathrm{~m}$. No other grid points are considered.

- Otherwise, of the four surrounding grid points, the one with the smallest height difference to the site is selected.

No height correction is made for precipitation. As will be shown later, there is no direct height dependence of the observed precipitation.

\section{VERIFICATION WITH HOURLY AND 6-HOURLY PRECIPITATION VALUES}

The verification is done at each ANETZ station for the associated SM grid point. A total of 69 ANETZ stations provide precipitation measurements, indicated by triangles in Fig. 3. The average distance between two stations is about $25 \mathrm{~km}$. The results are presented as a mean for all stations and for three topographic height classes. The routinely produced results of the hourly verification were available as mean diurnal cycles, mean error (bias), root mean square error and standard deviation of errors. Only the mean diurnal cycles will be presented here. The classification according to height classes (below $800 \mathrm{~m}, 800 \mathrm{~m}$ to $1500 \mathrm{~m}$, above $1500 \mathrm{~m}$ ) is done with the model elevation at the SM grid point.

\section{DIURNAL CYCLE OF HOURLY PRECIPITATION}

The model forecasts of four 3-month seasons were accumulated to diurnal cycles by averaging all forecasts for each hour of the forecast range. Because the forecast range was 48 hours, this yielded two consecutive daily cycles, the first representing forecast ranges 0 to 24 and the second 24 to 48 hours. The hourly observations of the ANETZ network 


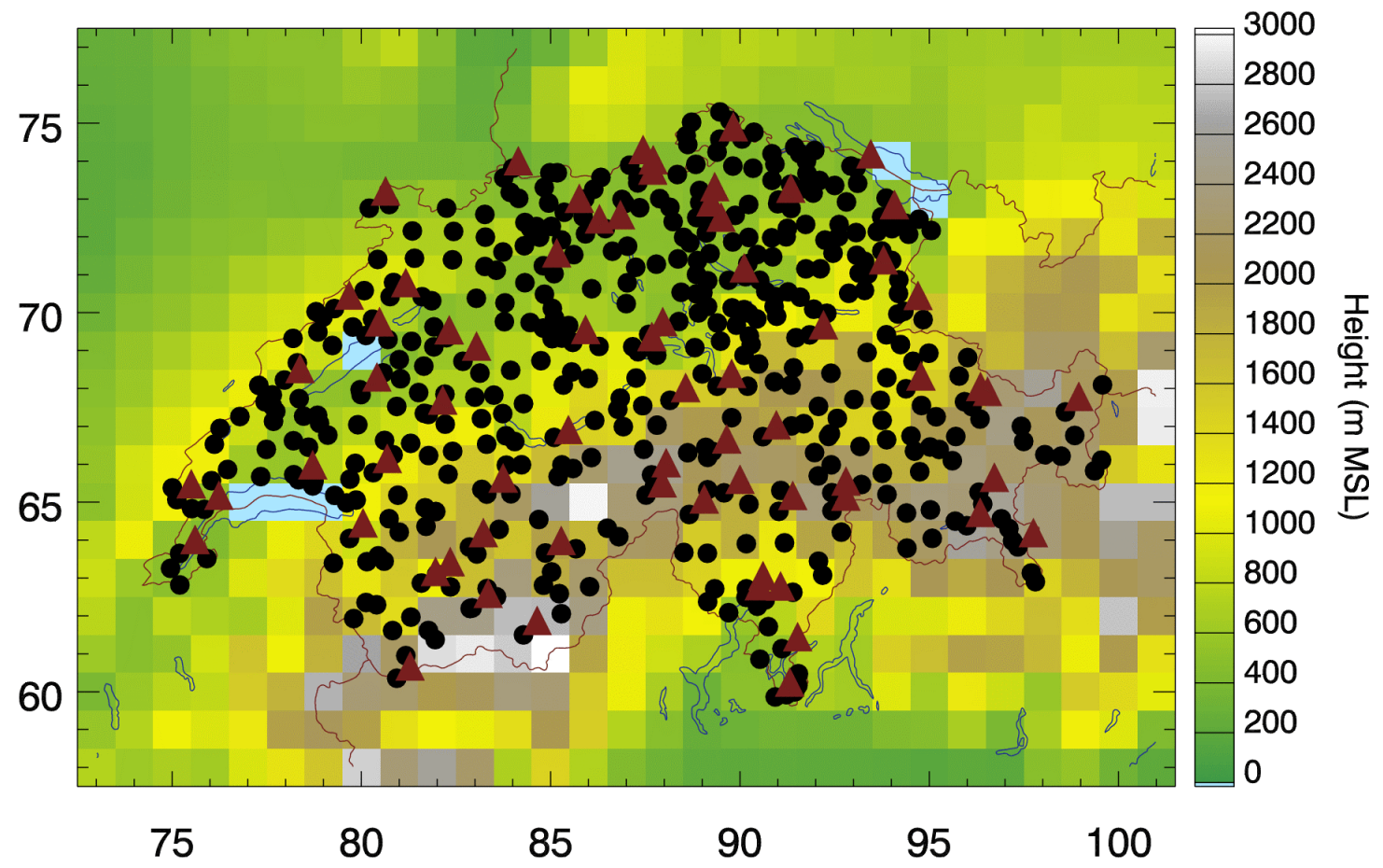

Fig. 3. Map of Switzerland with SM orography, showing locations of automatic hourly rain measurements (triangles) and rain gauge sites providing daily sums (dots).

were similarly averaged for each time of the day over all days of the season for which a forecast existed. To compare with the model forecast, this is also plotted as two daily cycles. If no forecast is missing, the two observed daily cycles are identical, otherwise, because the forecast range 24 to 48 is missing a day later than the range 0 to 24 , there might be small differences in the observed precipitation cycle of day 1 and day 2 .

\section{SCORES OF SIX-HOURLY TOTALS}

Scores for different thresholds values $t(0.1 \mathrm{~mm}, 2 \mathrm{~mm}, 5$ $\mathrm{mm}, 10 \mathrm{~mm}, 30 \mathrm{~mm}$ and $50 \mathrm{~mm}$ per $6 \mathrm{~h}$ ) were computed using 6-hourly totals of the ANETZ network. The values in the contingency table (Table 1) from which the scores are derived are $z$ the number of correctly predicted nonoccurrences (zero-events), $m$ the number of missed occurrences or non-detection, $f$ the number of false alarms or wrongly predicted occurrences, and $h$ the number of hits or correctly predicted occurrences.

The frequency bias (FBI) is a measure of over- and underestimation of precipitation for a given threshold $t$ and is the most useful score for an evaluation of the model behaviour. The percent correct rate (PEC) or hit rate gives the percent of cases lying in the diagonal of the contingency table: It is not well suited for high threshold values, when
Table 1. Contingency table. Obs: Observations, Fc: forecast, t: threshold.

\begin{tabular}{lll}
\hline & $O b s<t$ & $O b s \geq t$ \\
$\mathrm{Fc}<\mathrm{t}$ & $\mathrm{z}$ & $\mathrm{m}$ \\
$\mathrm{Fc} \geq \mathrm{t}$ & $\mathrm{f}$ & $\mathrm{h}$ \\
\hline
\end{tabular}

most cases are correctly predicted non-occurrences $z$. The false alarm rate (FAR) is a measure for false predictions. The probability of detection (POD) is sensitive to missed events. The latter two are especially useful scores for severe weather forecasts and show the balance in the trade-off between the two. A general overestimation of the precipitation leads to a high probability of detection, but also to a high false alarm rate, whereas a general underestimation yields a low false alarm rate but also a low probability of detection. Further scores (not shown here) were calculated such as the threat score (or critical success index) that is sensitive to both false alarm rates and missed events, giving a relative accuracy. The four scores for which results are presented in the next section are defined by

$$
F B I=\frac{f+h}{m+h}
$$




$$
\begin{aligned}
& P E C=\frac{z+h}{z+m+f+h} \\
& P O D=\frac{h}{m+h}
\end{aligned}
$$

and

$$
F A R=\frac{f}{f+h}
$$

\section{VERIFICATION WITH DAILY SUMS}

A dense network of raingauges is routinely available in Switzerland. They measure 24-h precipitation, accumulated from 06:00 UTC to 06:00 UTC the following day. The locations of some 450 stations in Switzerland are shown in Fig. 3 as black dots on the $14 \mathrm{~km}$ mesh of the SM orography. Not all of these stations are available concurrently but, on average, 446 were active during the verification period.

The raingauge network is in many places more dense than the SM mesh. Measurements of all stations assigned to the same model grid point were averaged. This procedure is similar to that described as upscaling observations by Cherubini et al. (2002). There is no other spatial interpolation and no height correction applied to the rainfall amounts. The 446 stations were assigned in this way to 184 model grid cells, so that, on average, 2.5 sites fell into a single cell. The stations, however, are not evenly distributed. The positioning of rain gauges is often along valley axes, where access is available. Hence, the SM grid points within the Alps, especially those representing high mountain ranges, are systematically left with few or no observations. Some $30 \%$ of the SM grid points within Switzerland have no corresponding site and thus there is no possibility of comparison with measurements.

The 24-h average of the SM was calculated with the forecast range +06 hours to +30 hours for the 00 UTC runs, and +18 hours to +42 hours for the 12 UTC runs. This avoids the concatenation of rainfall amounts from two different model runs because of possible inconsistencies between them.

The seasonal totals of precipitation were accumulated for each SM grid cell over three months, i.e. for summer, June, July, August and for winter, December, January, February. Plots of precipitation amounts versus altitude show independently the altitude dependency of modelled and real precipitation.

\section{Results}

The summer of 1997 was one of the wettest, while that of 1998 was dryer than average. For the winter seasons, 1995/
6 was representative of dry winters north of the Alps and wet south of the Alps, and 1999/2000 was wet north of the Alps and dry south of the Alps.

\section{DIURNAL CYCLES}

\section{Summer}

The summer of 1999 had average rainfall. Figure 4 shows the diurnal cycle of precipitation as derived from measurements (solid line) and from model forecasts (dashed line). The modelled precipitation has a very pronounced diurnal cycle, with peaks at 14-15 UTC on day 1 and one hour earlier on day 2 (Fig. 4a). A peak around 14 UTC is a common feature during all summer seasons for both the 00 UTC and the 12 UTC runs (not shown). The observed precipitation also shows a diurnal cycle but the amplitude is much smaller than that of the model forecast. In addition, the observed precipitation peak is much broader and is centred around midnight. Hence, the precipitation in the model starts too early, is too strong and then dies off too quickly. All other summers from 1993 to 2000 share similar characteristics to the summer of 1999 (not shown).

In the first few hours, the model precipitation falls sharply as can be seen in Fig. 4. This initial rainfall and the sharp drop-off are manifestations of the model spin-up effect. Because the model started with an interpolated analysis of the larger-scale model, the first few hours of each model run are contaminated by the artifacts created by inconsistencies in the interpolated fields. This spin-up can be eliminated if the model is initialised from its own assimilation cycle. This option was not available for the SM but is now in use for the successor model, the aLMo.

The model behaviour depends on the elevation of the model grid cell. If grid points below $800 \mathrm{~m}$ mean sea level (MSL) only are taken into account, the general overestimation of rainfall disappears, and the amplitude of the diurnal cycle is reduced to a realistic amount (Fig. 4b). The opposite effect takes place if grid points above $1500 \mathrm{~m}$ MSL only are taken into account. The model precipitation grossly overestimates the observed rainfall during the afternoon (Fig. 4c). This causes the large amplitude seen in Fig. 4a and demonstrates that overestimation of rainfall and the diurnal cycle are both connected to the orography.

This dependency of the model performance on the elevation at the grid cell remains the same for all eight summers from 1993 to 2000. The relative wetness of each season changes the precipitation scale of the respective figures, but not the model behaviour described.

\section{Winter}

The winter 1997/1998 was about average on both sides of 
(a)

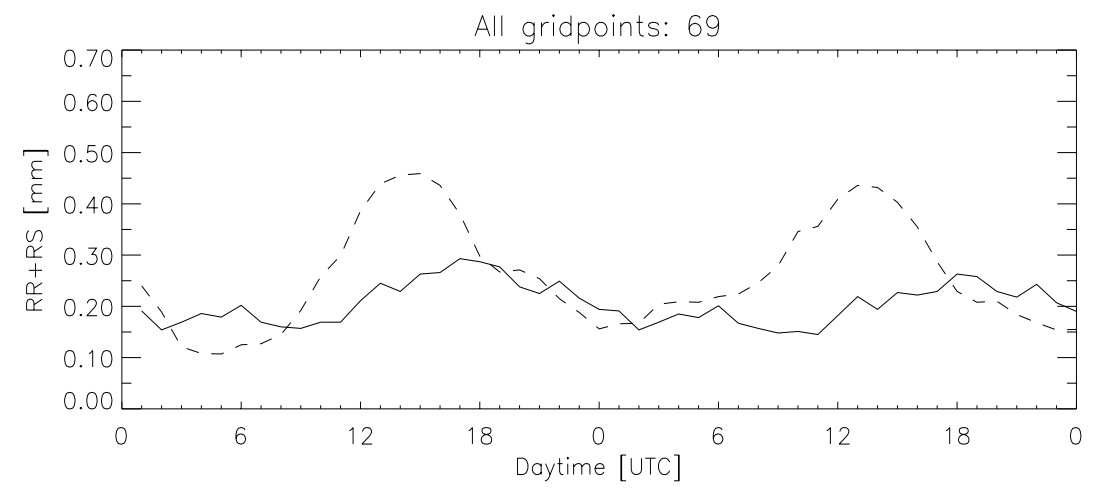

(b)

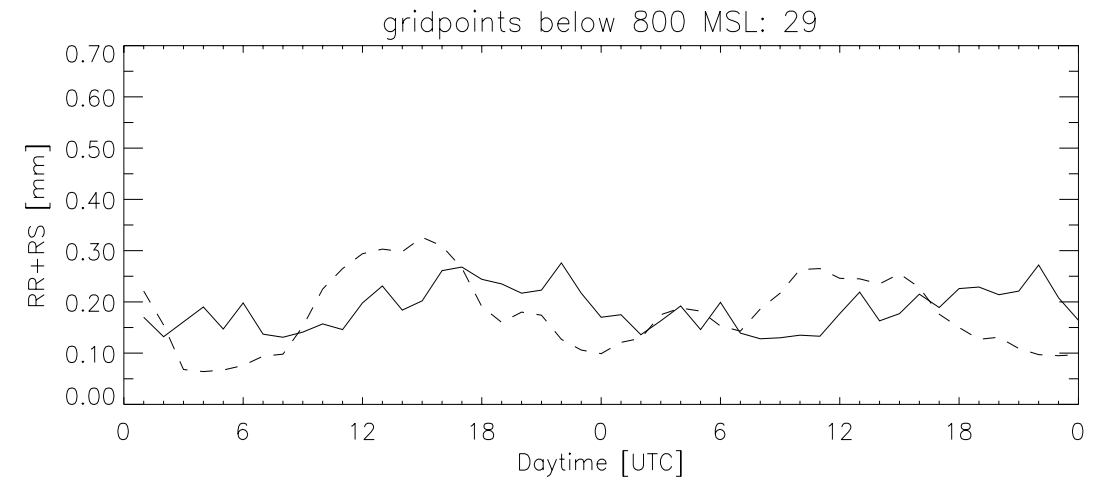

(c)

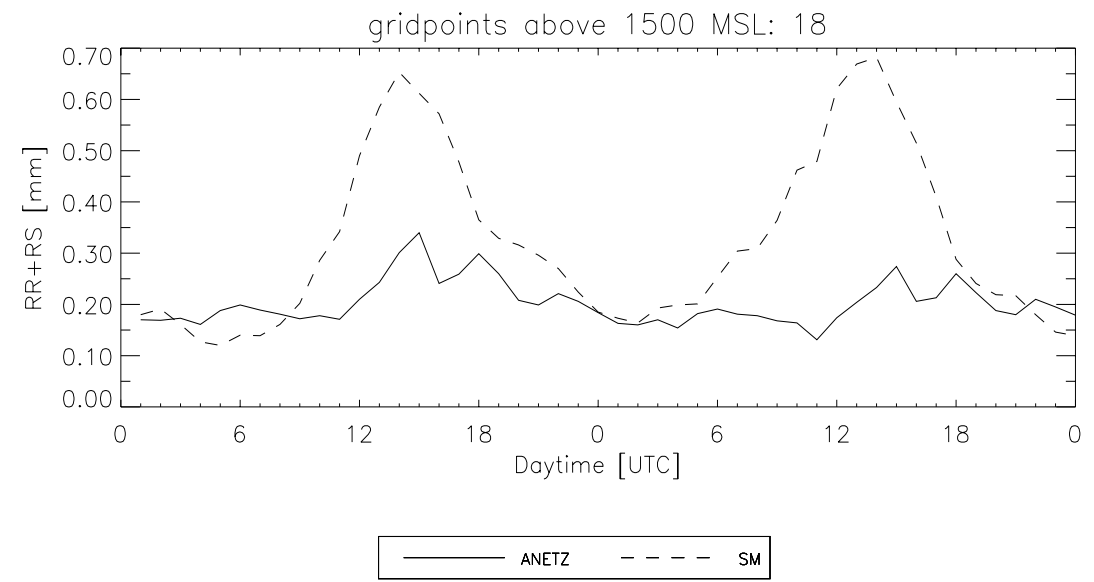

Fig. 4. Verification of diurnal cycle of rain from the SM runs with 00 UTC initial time for Summer 1999. (a) all grid points, (b) below $800 \mathrm{~m}$, (c) above $1500 \mathrm{~m}$ MSL. RR+RS stands for the sum of rain (RR) and snow (RS), i.e. the total precipitation. Solid line: ANETZ observations; dashed line: SM forecasts.

the Alps and is taken to represent the characteristics of all eight verified winters from 1993/1994 to 2000/2001. Figure 5 shows the observed and measured daily cycle for that winter. In contrast to the summer season, the two curves show an overall good correspondence (Fig. 5a). The visible diurnal cycle appears in several winters but its peak occurs at varying times and with varying amplitudes (not shown). In fact, this is not a real diurnal cycle at all but a few fronts that happen to pass, by chance, at approximately the same time of day. As in the summer, strong precipitation in the first hour and a sharp drop-off is evident at the beginning of the model run due to spin-up effects. The overall good performance of the model is slightly reduced when looking at the height classes separately: The model tends to underestimate precipitation at grid points below $800 \mathrm{~m} \mathrm{MSL}$ (Fig. 5b) whereas the general amount is about correct above $1500 \mathrm{~m}$ MSL (Fig. 5c). The larger deviation in the latter figure is due to the much smaller sample size than in Fig. 5 a. 
Precipitation Summer 1998 OOUTC forecasts

(a)

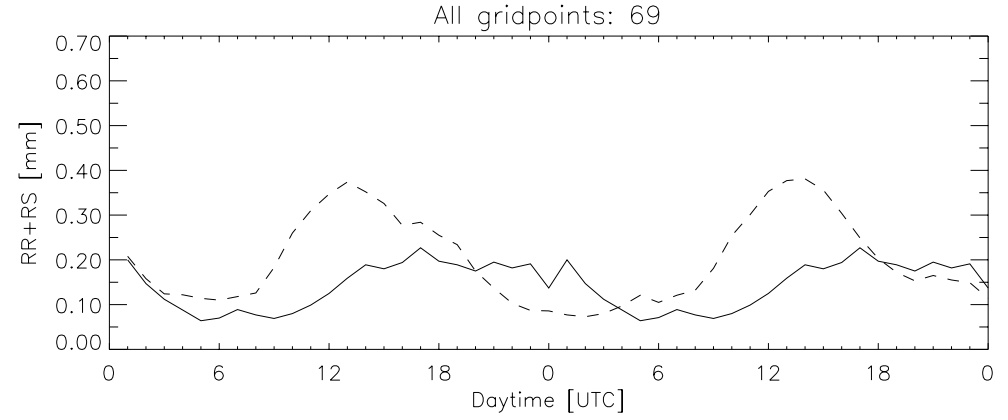

(b)

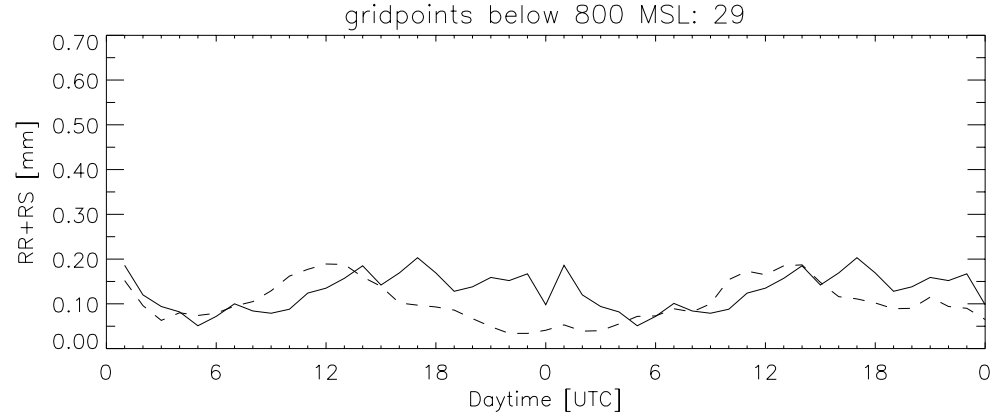

(c)

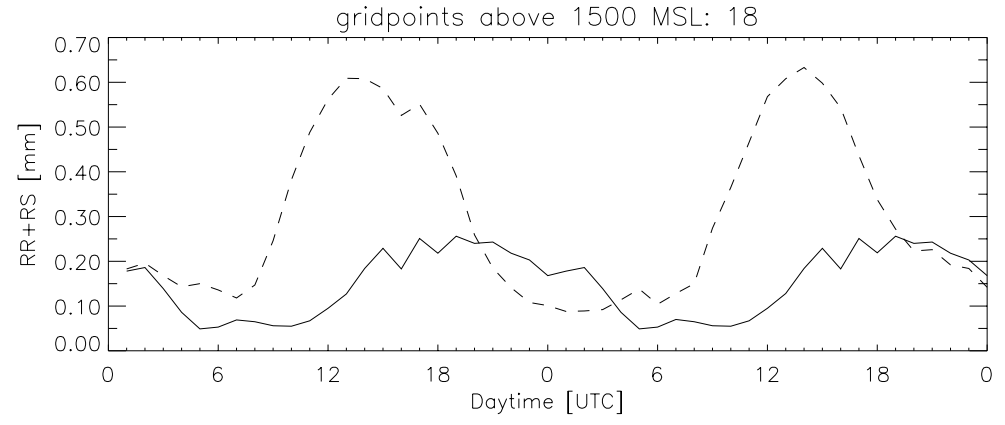

- ANETZ --- SM

Fig. 5. As for Fig. 4 but for Winter 1997/1998.

When comparing all eight available winters from 1993/ 1994 to $2000 / 2001$, there seems to be a tendency to underestimate at higher elevations, but the variation from year to year is quite large (not shown). The model bias for the height class from $800 \mathrm{~m}$ to $1500 \mathrm{~m}$ MSL, omitted here, is usually between the low and the high elevation class.

\section{SEASONALLY ACCUMULATED PRECIPITATION}

Over the period 1993-2001, from verified three-month periods representing summer and winter only, a pair representative of each of the two ends of the dryness scale was selected.

\section{Summer}

Figure 6 shows the simulated (left panels) and the observed (right panels) precipitation interpolated onto the SM grid for the summers 1997 and 1998. The values are seasonally accumulated rainfall amounts, interpolated by a simple averaging procedure as described earlier. The two summers represent the spatial and temporal variability of the precipitation amounts of the full sequence 1993 to 2000 (not shown). The rainfalls on the south and the north sides of the Alps vary independently. On the north-east side of the Alps, 1993, 1995, 1997 and 2000 were wetter than usual, whereas on the south side, 1996, 1997, and partially 1999 were wetter than usual years. The precipitation amount over the Jura Mountains along the north-west boundary of Switzerland and the western Swiss Middleland between the Jura and the Alps are wettest 1996, 1997 and 1999. Although this region is on the north side of the Alpine ridge, it seems to see some of the same influences as the south side rather 


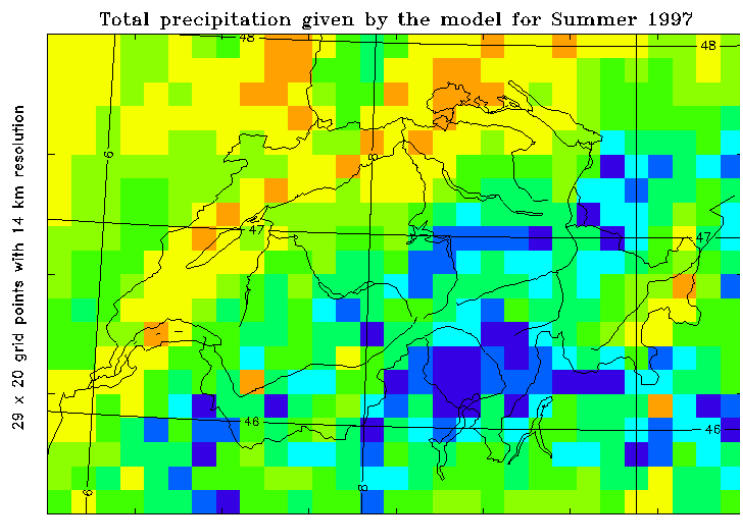

Precipitation in $[\mathrm{mm}]$ (maximum $=1835 \mathrm{~mm}$ )
Model Initial Time 0 UTC. Forecast Range 6 to 30

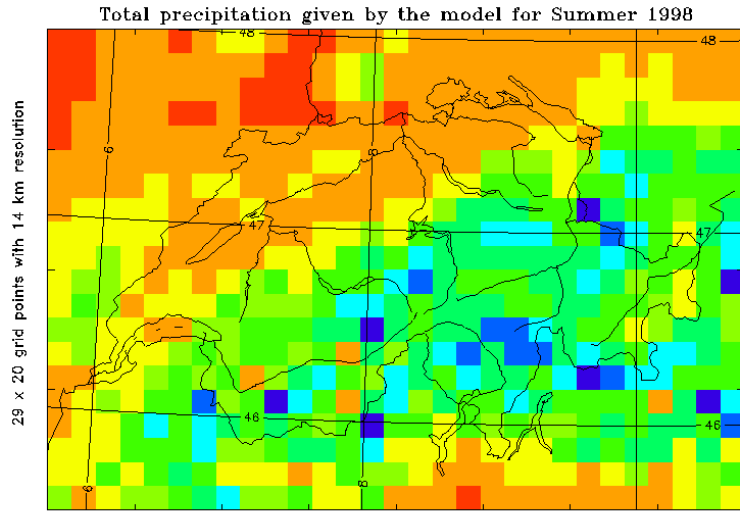

Precipitation in $[\mathrm{mm}]$ (maximum $=1705 \mathrm{~mm}$ )

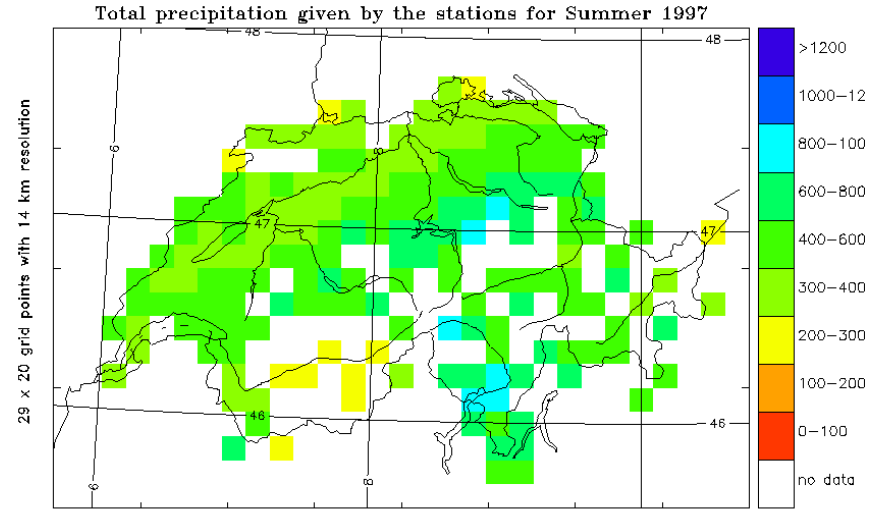

Precipitation in $[\mathrm{mm}]$ (maximum $=948 \mathrm{~mm}$ )

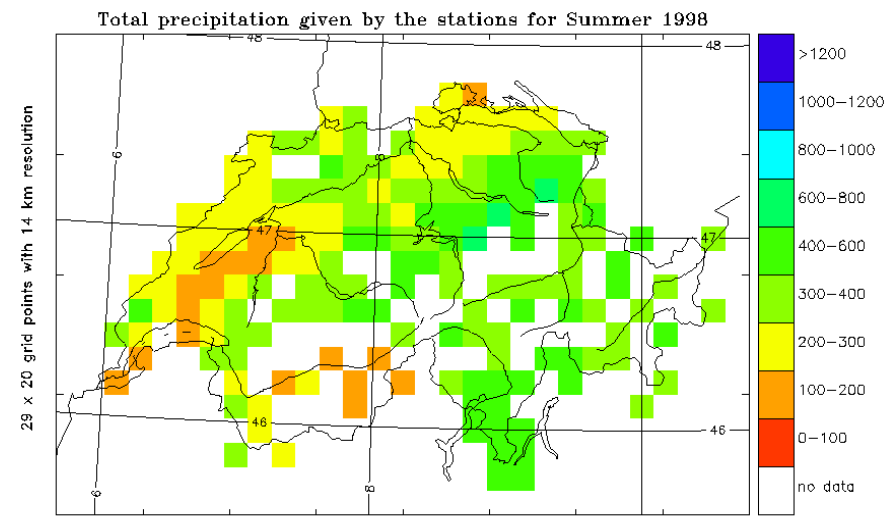

Precipitation in $[\mathrm{mm}]$ (maximum $=658 \mathrm{~mm}$ )

Fig. 6. Seasonally accumulated precipitation for summer 1997 (Panels a, b) and summer 1998 (c, d). Left (a, c): model forecast range +06 to +30 hours; right $(b, d)$ : observations.

than that of the north-east. A possible reason for this pattern could be Föhn situations, when the approaching cold front is slowed down over the western part of Switzerland, producing precipitation in the west and the prefrontal southerly flow causing precipitation south of the Alps, while the north-east remains dry.

Comparing the two columns in Fig. 6, it has to be considered that observations are missing outside the Swiss boundaries and at high elevations in the Alps. In general, the overall precipitation pattern is well captured by the model and the amounts at lower elevations are within 100-200 $\mathrm{mm}$ correct. However, the effect of the orography is overemphasised by the SM. The precipitation in the Alps is clearly too heavy; this is caused by the too strong convective precipitation in the mountains.

The spatial distribution shows coherent rainfall amounts of SM except for the summer 2000, where a strongly increased grid point to grid point variability occured (not shown). The most probable cause for this change in model behaviour is the new model configuration starting in September 1999 with the addition of 11 model levels in the vertical and an Eulerian instead of a semi-Lagrangian advection scheme. A separate summation of grid scale and convective precipitation shows that while the major part of summer precipitation is produced by the convective precipitation, both fractions show the strongly structured pattern. If the pattern were random noise, it would not show up in the seasonal total. In fact, the pattern is strongly related to the orography and, more specifically, to the steepness and exposure of the slopes.

Figure 7 shows the height dependence of the precipitation for both the model (crosses) and the observations (squares). In both cases, there is no height dependency of the values apparent. Only the precipitation of the model at each height shows an upper limit that seems to be vaguely height dependent. Such a height dependency is not visible for the observations. This is consistent with the findings of Frei and Schär (1998) who found a wet rim around the main 
Alpine ridge and a dryness anomaly within the Alps rather than a linear height dependency.

\section{Winter}

Figure 8 shows, similar to Fig. 6 above, the seasonal rainfall given by the model on the left hand side and the corresponding observed precipitation on the right hand side. Comparing the winter with the summer observations, there is a generally higher variability between different years in winter. The independency of the precipitation on the north and south sides of the Alps is more evident (not shown). The wettest winter on the north side was 1994/95, followed by 1999/2000 and 1998/99, all of which were at the same time the driest winters south of the Alps. The winter 1993/ 94 was wet on both sides of the Alps, whereas 2000/01 was wetter than average mainly on the south side.

The model shows a large variability from grid cell to grid cell as compared to the measurements. It should be expected that seasonal totals of $14 \mathrm{~km} \times 14 \mathrm{~km}$ spatial averages would produce a relatively smooth precipitation pattern rather than this high spatial variability. This is a problem for the forecaster who has to interpret the precipitation charts. The experience with the higher-resolution successor model shows that the variability increases with horizontal resolution. How this was solved in the successor model is described later.

Figure 9 shows the dependency of the rainfall amount on the elevation. As in summer, there is no dependency visible except for the upper limit in the model precipitation. The observed precipitation is smaller than in summer. Only one observation is over $500 \mathrm{~mm}$, compared to the summer 1997 when amounts were up to $1000 \mathrm{~mm}$ (Fig. 7). In winter, undercatch of snowfall is a problem especially at higher elevations. The relatively small precipitation amounts observed at some higher elevation sites might be influenced by this.

\section{SEASONAL SCORES}

Figure 10 shows the scores for 1994-2001 for the threshold $0.1 \mathrm{~mm} / 6 \mathrm{~h}$, for the summer and winter seasons. These scores were not calculated during the pre-operational phase in 1993 and, unlike the accumulated precipitation verification, cannot be reconstructed. The seasons before September 1995, indicated by dotted lines in Fig. 10, are expected to have slightly better scores due to the shorter forecast range. The scores shown are calculated using all 6hourly sums from the model except the first to avoid the period influenced by the model spin-up. The resulting scores vary widely from year to year and no general trend can be

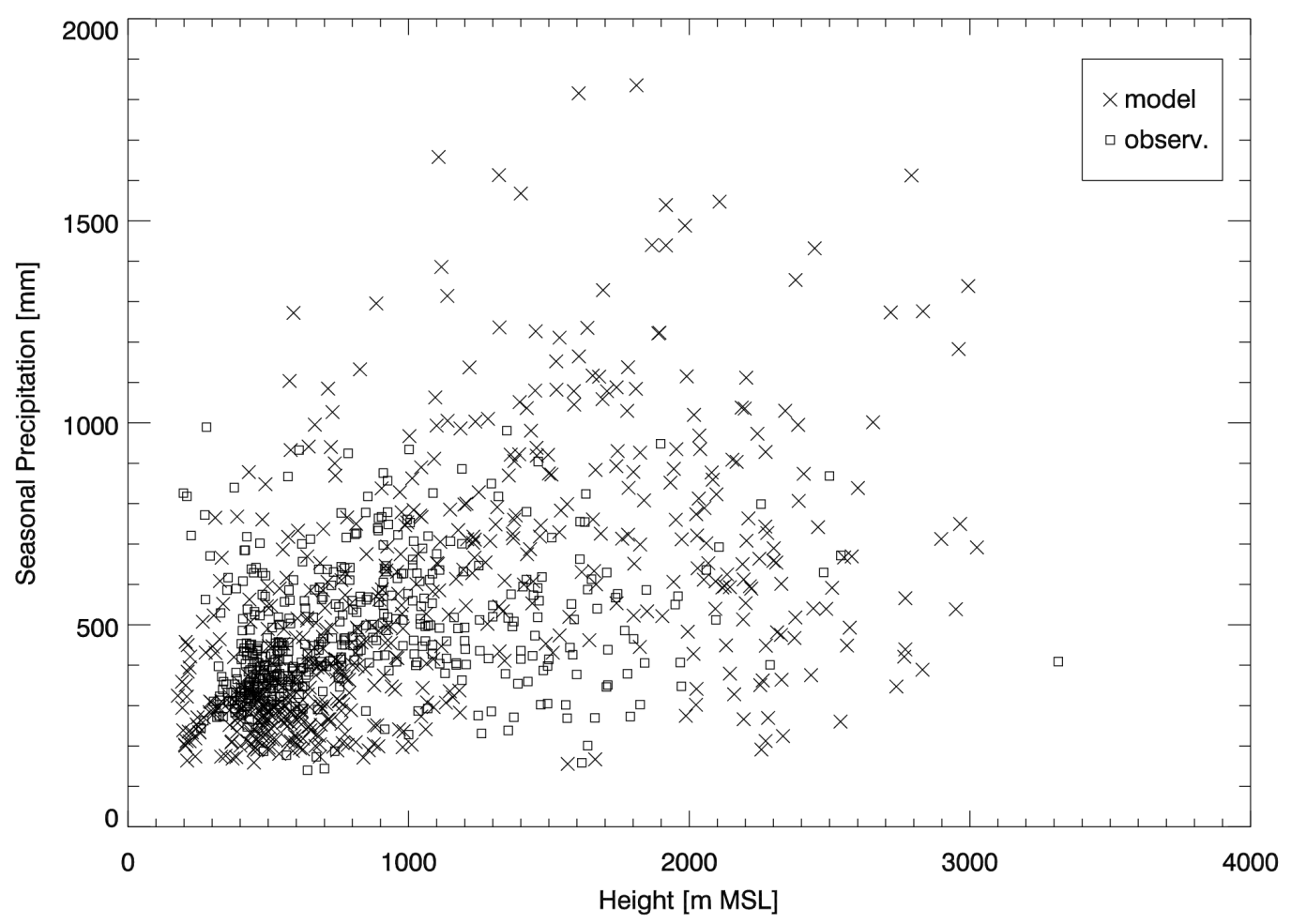

Fig. 7. Height dependence of precipitation in Summer 1997. Crosses: model precipitation, squares: observations. 


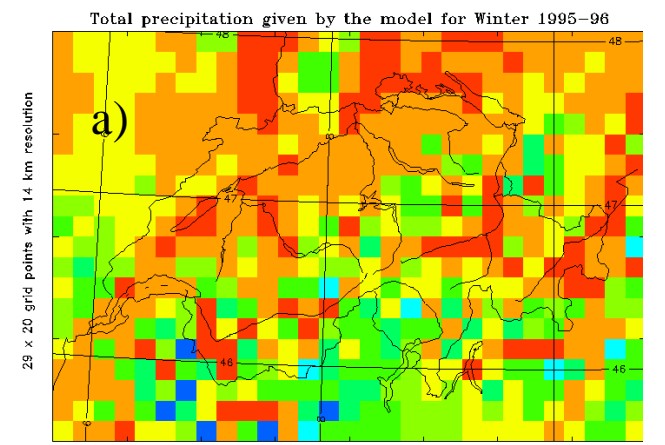

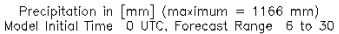

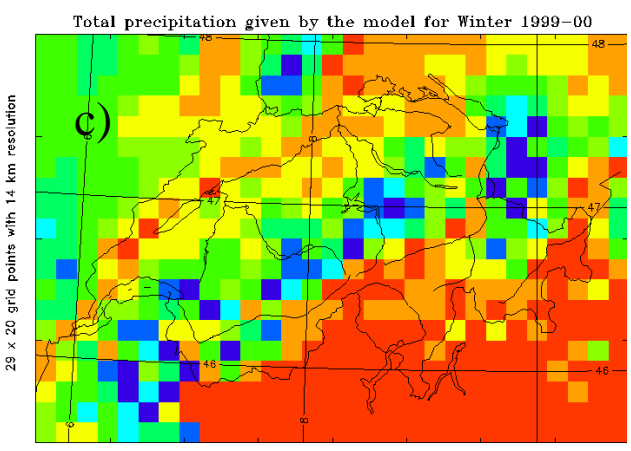

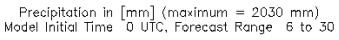
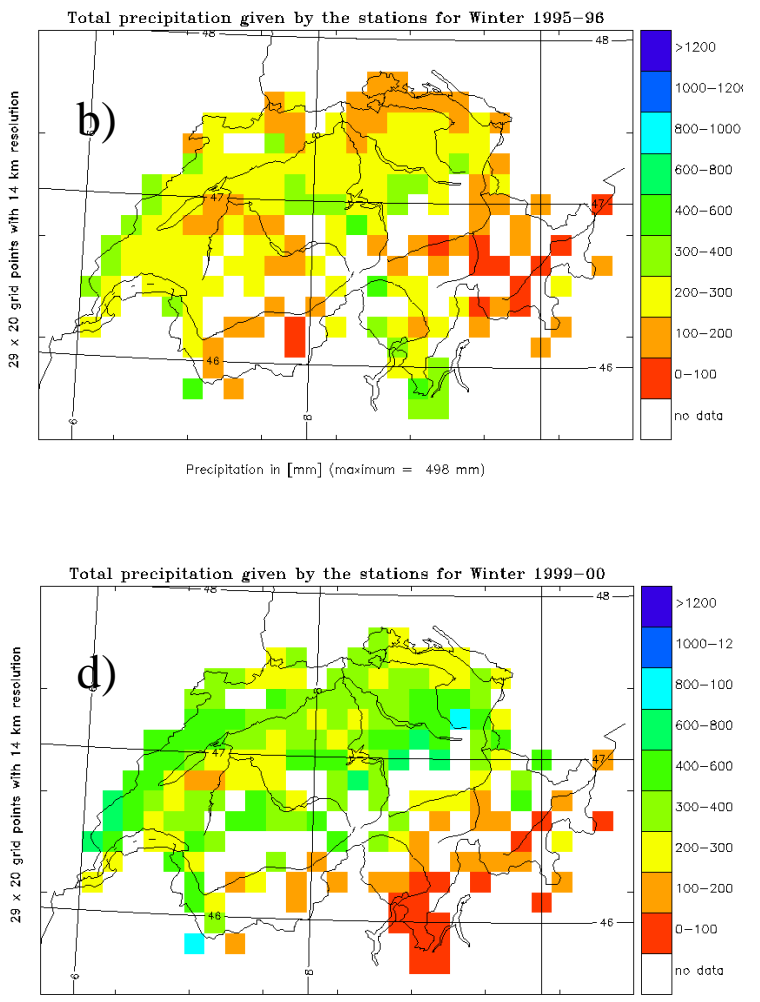

Precipitation in $[\mathrm{mmm}]$ (maximum $=870 \mathrm{~mm}$ )

Fig. 8. Seasonally accumulated precipitation for Winter 1995/1996 (Panels a, b) and Winter 1999/ 2000 (Panels $c, d$ ). Left column $(a, c)$ : model forecast range +06 to +30 hours; right column $(b, d)$ : observations.

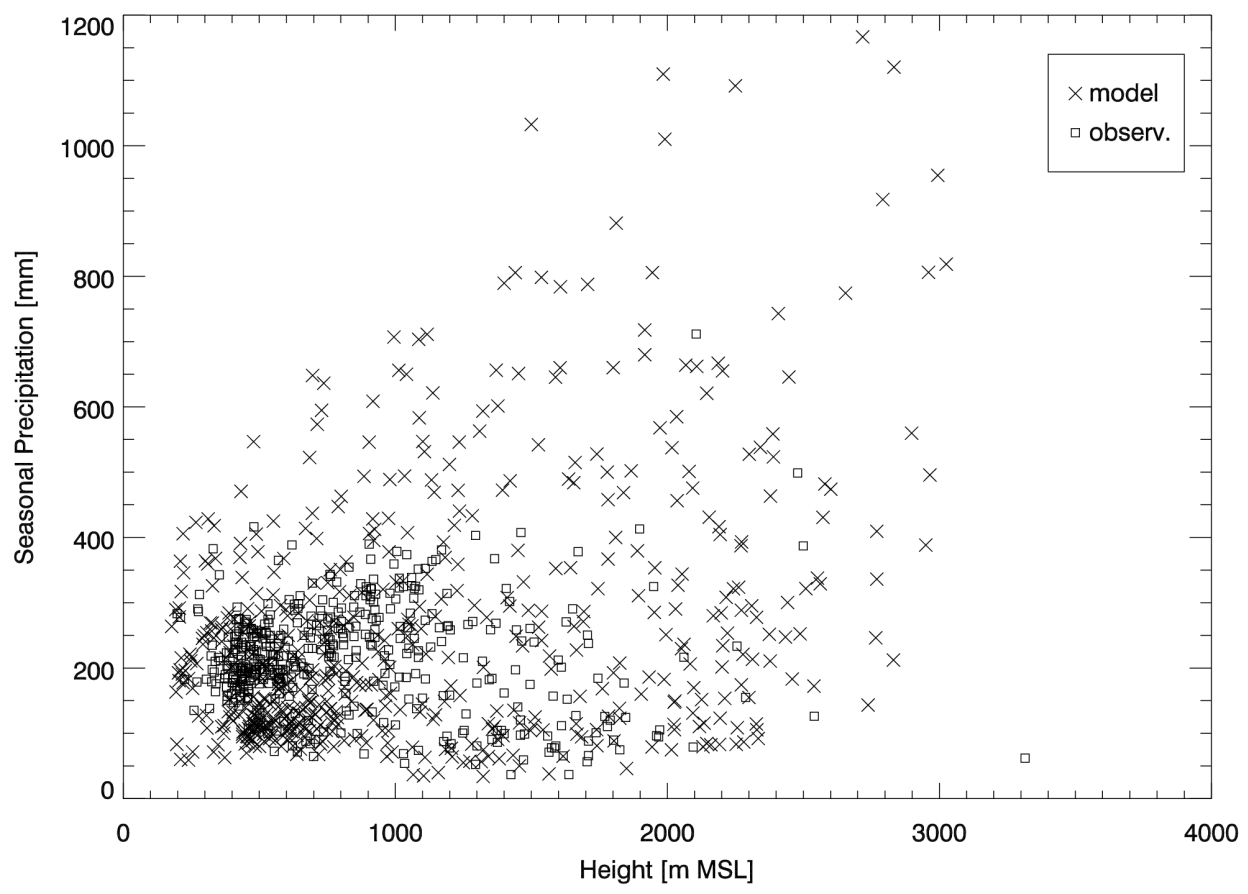

Fig.9. Height dependence of precipitation Winter 1995/1996. Crosses: model precipitation, squares: observations. 
deduced. The impact of the increased vertical resolution starting in September 1999 (dotted lines) on precipitation also seems negligible.

The frequency bias (Fig. 10a) shows a constant overestimation of rain occurrence in the winter season. In summer, the values are always smaller and the bias tends to decrease over the years. The percent correct rate (Fig. 10b) however does not improve with time but has a large yearto-year variability because of the large variability in the occurrence of precipitation. The probability of detection (Fig. 10c) shows a clear distinction between winter and summer performance. Here, the last winter has a somewhat reduced probability of detection. In this dry winter with relatively short, intermittent precipitation episodes, it is more difficult for the model to predict correctly the on- and offset of the episodes than in a wet winter with longer rain episodes.

Figure 10d finally shows the false alarm rate. Here, the perfect forecast would be $0 \%$ rather than $100 \%$ as in the previous scores. The winter forecasts are often better than the summer forecasts, but the last winter shows the worst value of all, probably due its dryness.

Table 2 shows the frequency bias separately for five threshold values and three height classes, for the summer 1997 and winter 1999/2000. The scores for the high threshold values must be used with care because only very few cases greater than $10 \mathrm{~mm} / 6 \mathrm{~h}$ occurred: $3.3 \%$ of all cases in summer 1997, and only $1.4 \%$ of all cases in the winter 1999/2000. In winter 1999/2000, there were no observed cases exceeding $50 \mathrm{~mm} / 6 \mathrm{~h}$, so the scores are not defined and are denoted with NA (not available) in the table.

There are four interesting points, typical for each summer or winter season of the period 1994-2001, demonstrated in Table 2 by the two seasons of summer 1997 and winter 1999/ 2000 , both being wetter than average:

1. In summer, the $00 \mathrm{UTC}$ forecasts produce about $10 \%$ more precipitation than the 12 UTC forecasts. The frequency bias for the $00 \mathrm{UTC}$ forecasts is higher for all threshold values. The two possible reasons are either misrepresentation of the convective peak in the afternoon of the first forecast day when starting at 12 UTC, or different surface values as initial conditions from the driving EM model.

2. In summer, the precipitation is underestimated for grid
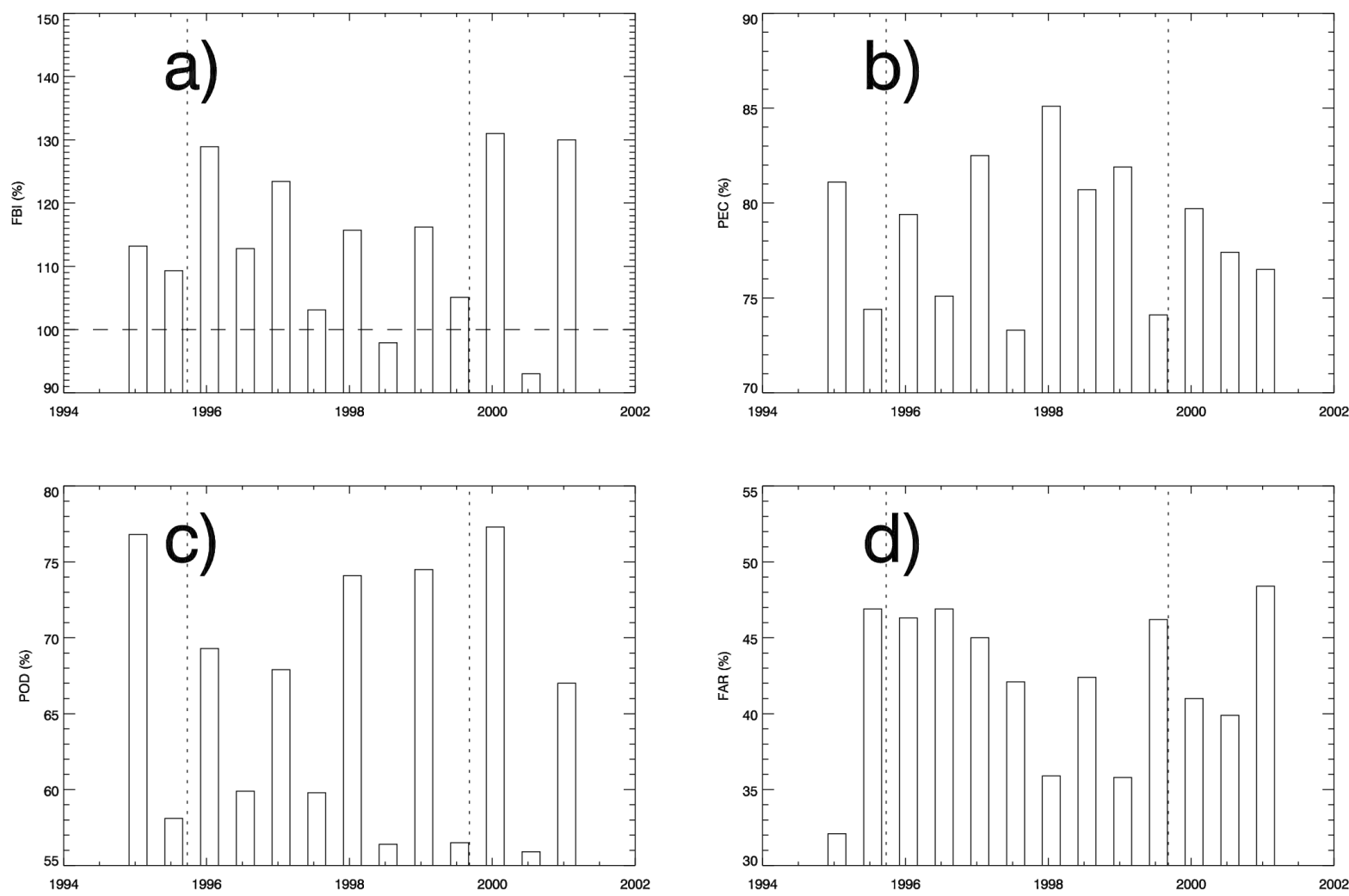

Fig. 10. Seasonal precipitation scores for Summer and Winter, $1994-2001$. The first vertical dotted line is drawn where the forecast range changed from 36 to 48 hours, the second vertical line is the change from 20 levels Semi-Lagrangian to 31 levels Eulerian. The sores are (a) frequency bias (FBI), (b) percent correct (PEC), (c) probability of detection (POD), (d) and false alarm rate (FAR). The time axis labels mark the beginning of the respective year. 
Table 2. Frequency bias of the seven 6-hourly precipitation sums from $+6 \mathrm{~h}$ to $+48 \mathrm{~h}$ for different threshold values.

\begin{tabular}{lccccc}
\hline & \multicolumn{5}{c}{ Threshold $(\mathrm{mm} / 6 \mathrm{~h})$} \\
& 0.1 & 2.0 & 10.0 & 30.0 & 50.0 \\
\hline $\begin{array}{l}\text { Summer 1997 } \\
\text { Initial time 00 UTC }\end{array}$ & 108.0 & 108.3 & 143.0 & 243.1 & 415.4 \\
Summer 1997 & 98.1 & 99.5 & 134.5 & 175.9 & 200.0 \\
Initial time 12 UTC & & & & & \\
Summer 1997 & 93.6 & 91.3 & 94.8 & 100.0 & 242.9 \\
Grid cells below 800 m & & & & & \\
Summer 1997 & 114.6 & 123.8 & 183.9 & 305.4 & 253.8 \\
Grid cells above 1500 m & & & & & \\
Summer 1997 & 103.1 & 104.0 & 138.9 & 209.7 & 307.7 \\
All & & & & & \\
Winter 1999/2000 & 131.0 & 103.6 & 86.4 & 84.8 & NA \\
All & & & & & \\
Winter 1999/2000 & 126.4 & 99.6 & 80.5 & NA & NA \\
Grid cells below 800 m & & & & & \\
Winter 1999/2000 & 137.4 & 128.2 & 128.0 & 138.9 & NA \\
Grid cells 800-1500 m & & & & & \\
$\begin{array}{l}\text { Winter 1999/2000 } \\
\text { Grid cells above 1500 m }\end{array}$ & 130.6 & 73.6 & 39.0 & 46.4 & NA \\
\hline
\end{tabular}

points below $800 \mathrm{~m}$ but strongly overestimated in the mountains (grid points above $1500 \mathrm{~m}$ ).

3. In summer (all altitudes), the small precipitation amounts (threshold $0.1 \mathrm{~mm} / 6 \mathrm{~h}$ ) are predicted correctly, but the large amounts $(\geq 10 \mathrm{~mm} / 6 \mathrm{~h})$ are overestimated by $40 \%$. The contrary is true in winter. Small amounts are overestimated (by about 30\%) and high amounts are underestimated (by 15\%). This is the result of precipitation areas that in winter are too large with too low maxima, while in summer the precipitation areas are too small (except over the mountains) and the maxima over mountains are too high.

4. In winter, precipitation $\geq 2 \mathrm{~mm} / 6 \mathrm{~h}$ is overestimated only in the Alpine foothills ('Prealps', grid cells $800-$ $1500 \mathrm{~m}$ ) by about $30 \%$; above and below this altitude, the precipitation is underestimated, especially for amounts $(\geq 10 \mathrm{~mm} / 6 \mathrm{~h})$. This is the result of the tendency of the model to give too much precipitation on the upwind side of the mountains, where the flow impinges on the Jura hills along the north-west boundary of Switzerland and the Alps.

\section{Case studies}

\section{PROJECT RAPHAEL}

Severe flooding is a high risk in the Alps and often leads to great property damage and sometimes to the loss of life. An integrated flood forecasting system could be envisioned (Volkert, 2000) that provides warning ahead of time and allows for timely precautions. To tackle the problem of flood forecasting in the mountains, a group of 11 institutes from Europe and Canada started the project RAPHAEL (Runoff and Atmospheric Processes for flood Hazard forEcasting and controL). This EU-funded project was planned within the framework of the Mesoscale Alpine Programme (MAP) (Bougeault et al., 2001).

The focus of RAPHAEL was to demonstrate the use of a one-way coupled system of atmospheric and hydrological models for flood forecasting. An important aspect was the indirect verification of the precipitation forecast of the numerical weather prediction model. Instead of comparing model precipitation directly with the observations, the coupled system was used to compare the simulated and observed runoff from a catchment as an integrated measure depending on the total rainfall on the catchment area. This type of validation is described elsewhere (Jasper et al., 2002; Jasper and Kaufmann, 2003; Benoit et al., 2002). In the present paper, a direct comparison will be made of the SM precipitation output from varying model versions with observations.

Four events of heavy precipitation on the south side and four events on the north side of the Alps were chosen as test cases for RAPHAEL. Only the four events selected for the south side of the Alps will be considered here. Table 3 summarises the simulations for the RAPHAEL standard mode simulations. It indicates the initial times of the individual meteorological model runs from which the data for the hydrological models were generated.

For the SM output provided to the hydrological models, a sub-domain within the SM grid was defined (solid frame in Fig. 1). It was named Ticino-Toce area after the two main contributing rivers to the lake (the Lago Maggiore). The rectangular box contains $11 \times 10$ grid cells with a total area of $21000 \mathrm{~km}^{2}$. This area contains the catchment area of the Ticino to the outlet dam of the Lago Maggiore in Miorina.

The SM hourly precipitation is presented as catchmentaverage on the assumption that the rain falls uniformly within each SM grid cell with an area of approximately 196 $\mathrm{km}^{2}$. No interpolation of the model rainfall was done. The average rainfall for the Ticino at Miorina catchment was calculated by weighting each grid cell by the fraction of the grid cell within the catchment boundary. The values of this weighting are given by Kaufmann (2002). Each episode 
Table 3. List of events in project RAPHAEL for the Ticino catchment with SM initial times and simulation ranges.

\begin{tabular}{|c|c|c|}
\hline Event & Initial timesUTC & $\begin{array}{c}\text { Simulation range } \\
\text { (h) }\end{array}$ \\
\hline $\begin{array}{l}\text { September 1993, } \\
\text { 'Brig' case }\end{array}$ & $\begin{array}{ll}1993-09-21 & 12: 00 \\
1993-09-22 & 12: 00 \\
1993-09-23 & 12: 00\end{array}$ & $\begin{array}{l}36 \\
36 \\
36\end{array}$ \\
\hline $\begin{array}{l}\text { October 1993, } \\
\text { 'Locarno' case }\end{array}$ & $\begin{array}{l}1993-10-11 \text { 12:00 } \\
1993-10-1300: 00\end{array}$ & $\begin{array}{l}48 \\
48\end{array}$ \\
\hline $\begin{array}{l}\text { November 1994, } \\
\text { 'Piemonte' case }\end{array}$ & $\begin{array}{l}1994-11-03 \text { 00:00 } \\
\text { 1994-11-04 00:00 } \\
1994-11-0500: 00\end{array}$ & $\begin{array}{l}36 \\
36 \\
36\end{array}$ \\
\hline $\begin{array}{l}\text { June 1997, } \\
\text { 'Snowmelt' case }\end{array}$ & $\begin{array}{l}1997-06-2612: 00 \\
1997-06-2800: 00\end{array}$ & $\begin{array}{l}48 \\
48\end{array}$ \\
\hline
\end{tabular}

consists of 2-3 model runs according to Table 3 . The runs overlap 12 hours in time. This was done to avoid using the first 12 hours for hydrological simulations because of model spin-up effects.

The simulations were made in two modes, the forecast and the analysis mode. In addition, sensitivity studies evaluated the sensitivity of the model precipitation to the microphysical scheme, the vertical resolution, the advection scheme and the evapotranspiration process.

\section{SENSITIVITY TO DRIVING MODEL}

The analysis mode and the forecast mode of the SM differ in the driving lateral boundary values provided by the EM. In the forecast mode, which was the operational mode of the SM, the boundary conditions were provided hourly by the operational EM forecast. In the so-called analysis mode, the boundary conditions for the simulation were all provided at six-hourly intervals by the EM assimilation cycle. The SM analysis mode simulation itself did not assimilate observations.

The average precipitation predicted by these two simulation modes of the SM are presented in Fig. 11. Figure 11a shows the hourly average of the first of the selected episodes, the so-called 'Brig' case. This event is dominated by convective rainfall. The two SM modes agree well up to 23 September 1993 12:00 UTC. Figure 12 shows the spatial patterns of the two SM modes at that time. They are very similar and fit well with the observations (Fig. 12a, b). This time period has also been studied by Stein et al. (2000) applying a non-hydrostatic model with two horizontal resolution settings of $10 \mathrm{~km}$ and $2 \mathrm{~km}$ and finding a great improvement in the fine scale pattern in the high resolution run.

Later, at 22:00 UTC the same day, the forecast shows an excessive grid scale precipitation peak. The most intense precipitation occurs already 2 hours earlier in the southwesterly part of the Ticino-Toce area, but is not captured in the precipitation curve in Fig. 11a because it is outside the Ticino at Miorina catchment (Fig. 12c). It then moves towards NE into the catchment, thus the peak for the catchment average occurs two hours later. When compared to the observations, the forecast is clearly overpredicting this event. The corresponding analysis driven simulation (Fig. 12d) is still too high but much closer to the actual precipitation.

The forecast has again excessive precipitation towards the end of the episode (Fig. 11a), but this time in the convective fraction. Initially, the analysis mode positions the rainfall better than the forecast but then the rainfall in the analysis mode moves too quickly towards the east (Fig.13b) as opposed to the forecast mode (Fig. 13a).

In the second episode (Fig. 11b), there is a first peak at 12 October 1993 2:00 UTC in the forecast mode that is not present in the analysis mode. The observations do not support this increased rainfall (not shown). A second, more pronounced peak in the forecast on 14 October 01:00 UTC is also unrealistically high. The peak rainfall in the analysis occurs at the same time, but the amount fits better with the observations although the precipitation is a bit too far to the east (not shown).

Unlike the other episodes which are all dominated by convective precipitation, the third episode (Fig. 11c) is dominated by grid scale precipitation. The SM forecast produces a first peak, mostly from grid scale precipitation, on 4 November 1994 7:00 UTC. It overestimates the precipitation at that time, whereas the analysis fits well with the observations (not shown). The same is true for the next peak at 16:00 UTC. From 5 November 10:00 to 6 November 3:00 UTC the forecast has constantly more grid scale precipitation than the analysis. The amount of rain is clearly too high in the forecast and it moves too quickly to the northwest (Fig. 14a). The analysis mode has much better amounts and better positioning (Fig. 14b).

During the fourth episode (Fig. 11d), the forecast and analysis show very good agreement up to 28 June 1997 21:00 UTC except for a few hours after 27 June 18:00 UTC, where the precipitation in the analysis mode decreases more slowly than in the forecast. The observations indicate isolated thunderstorms at this same time (not shown). The analysis captures this as convective precipitation but the amount cannot be sensibly compared to observations due 

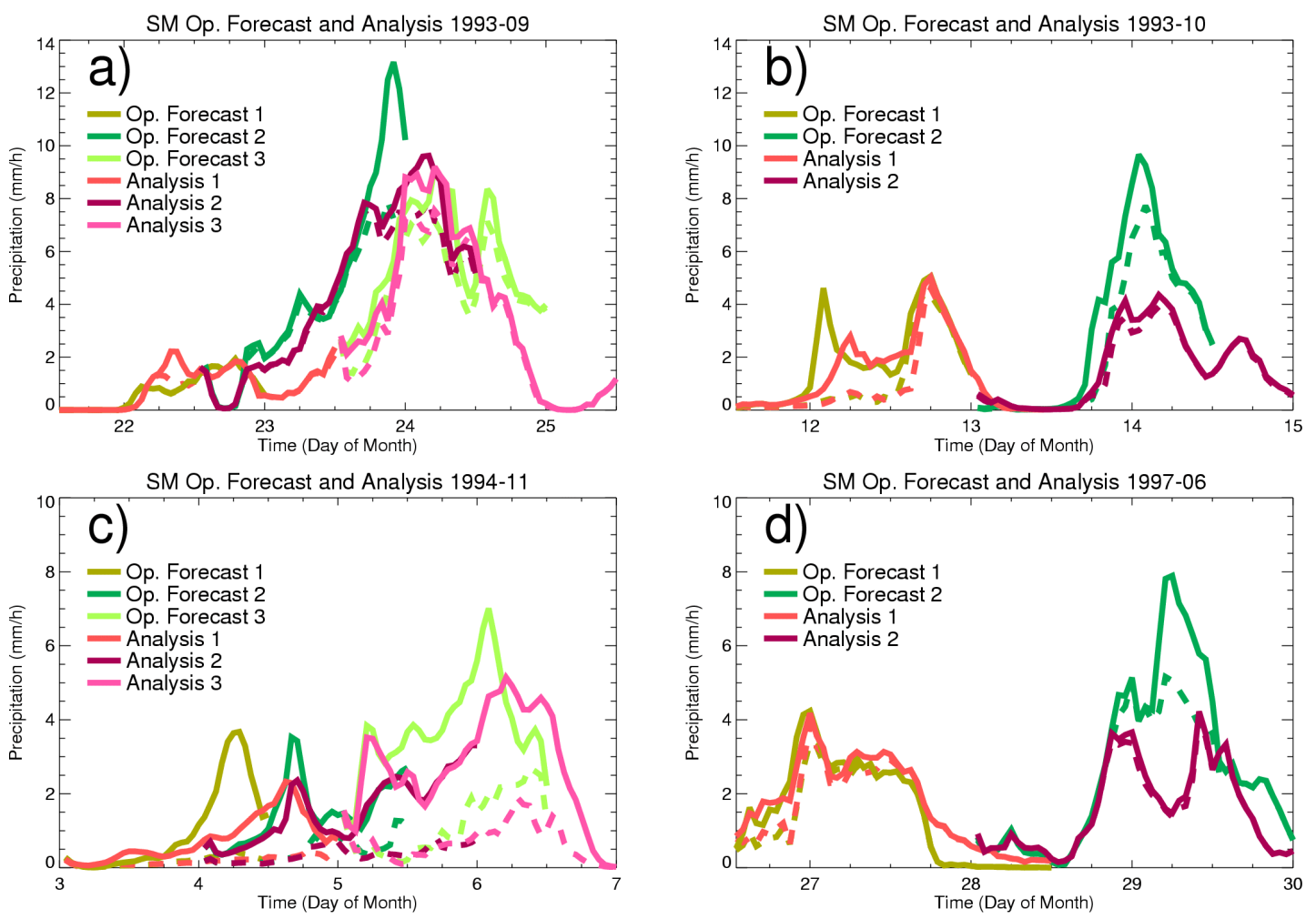

Fig. 11. Average precipitation over the Ticino at Miorina catchment for the SM forecast (shades of green) and analysis mode (shades of red), for the four Ticino-Toce episodes: (a) Brig, (b) Locarno, (c) Piemonte, (d) snowmelt case. The solid lines show the total precipitation, the dashed lines the convective fraction. The time axis labels mark the beginning of the respective day.

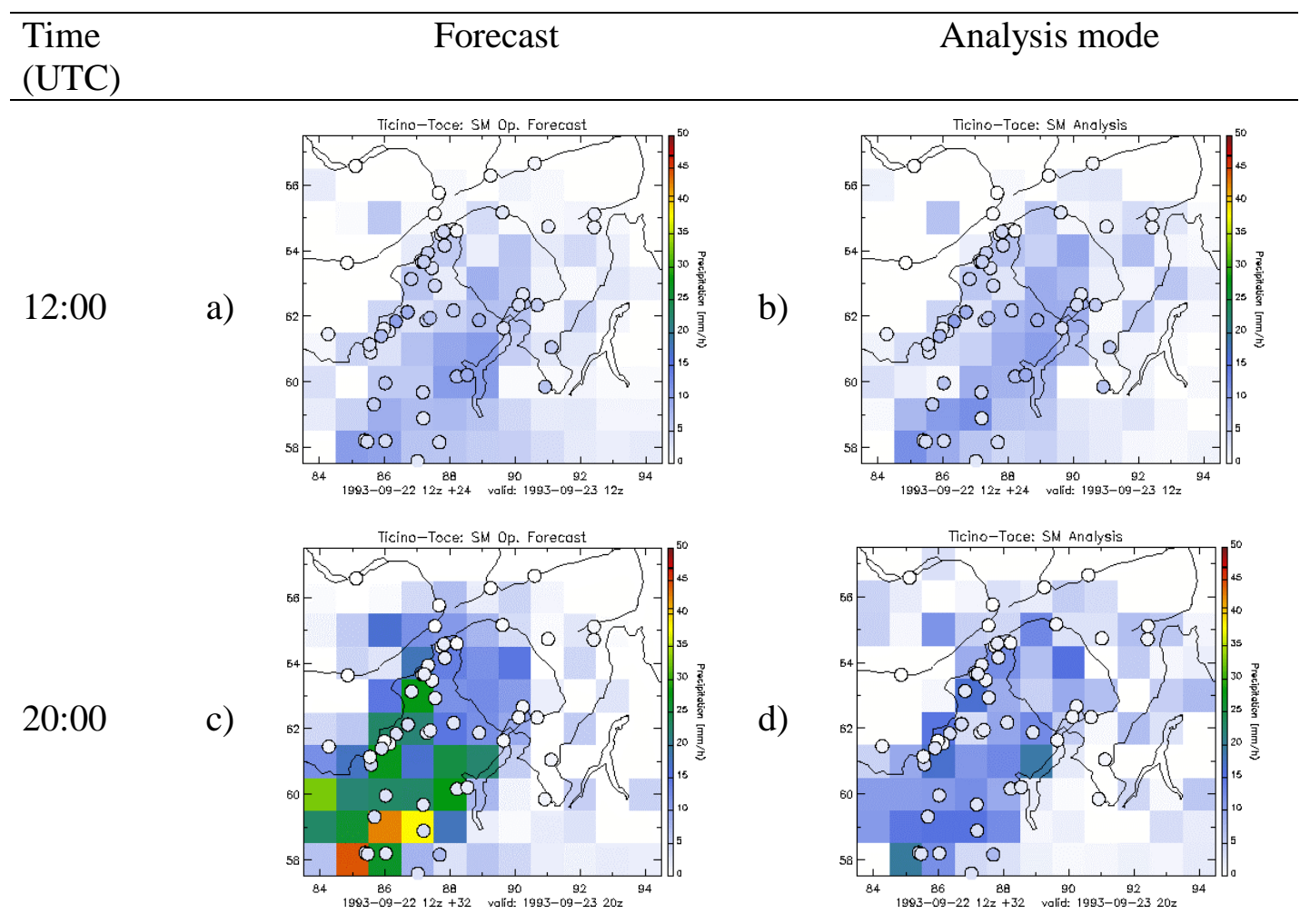

Fig. 12. Spatial distribution of 1-h precipitation at 23 Sep 1993 at 12:00 (a, b) and 20:00 UTC (c, d). Left panels (a, c): SM forecast mode, right panels $(b, d):$ SM analysis mode. Filled circles: 1-h observations. 


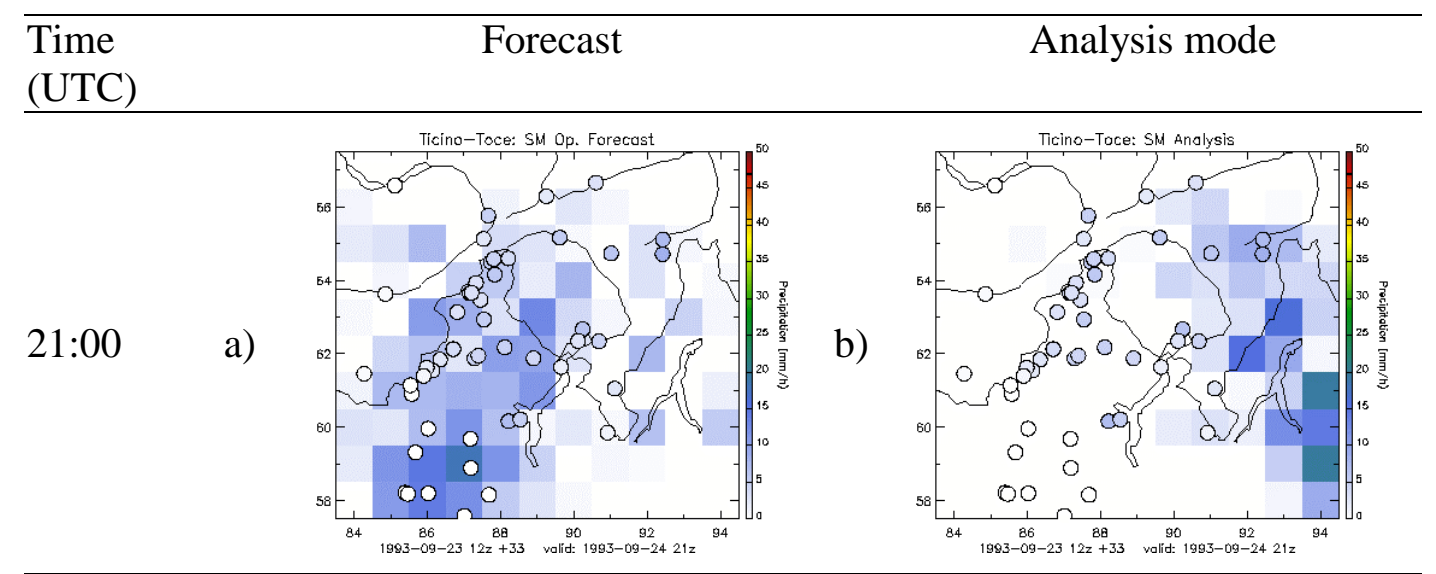

Fig. 13. Spatial distribution of 1-h precipitation at 24 September 1993 21:00 UTC of a) SM forecast; b) SM analysis mode. Filled circles: 1-h observations.

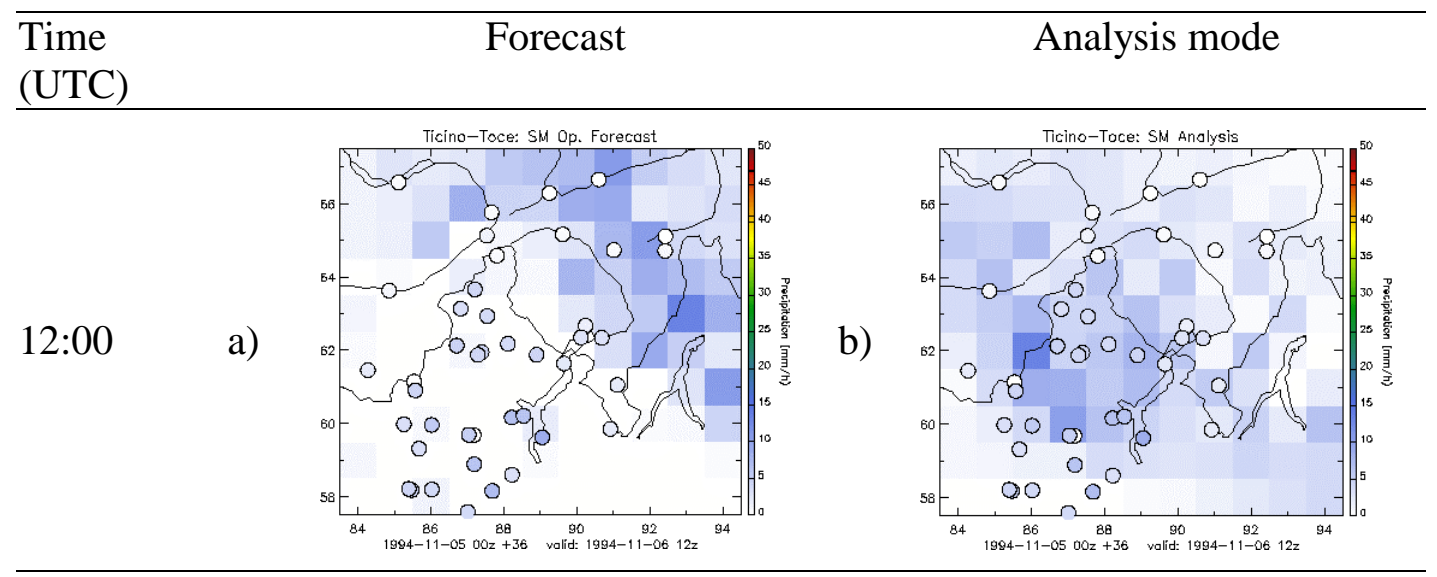

Fig. 14. Spatial distribution of 1-h precipitation at 6 November 1994 12:00 UTC for a) SM forecast, b) SM analysis mode. Filled circles: 1-h observations.

to the erratic nature of the observed rainfall. Later, for both modes, the onset of the next peak compares well with the observations (Fig. 15a, b). The forecast shows a high peak on 29 June 6:00 UTC whereas, in the analysis mode, the precipitation is receding at the same time. The forecasted pattern is not only too strong, but shifted towards the northeast by about $60 \mathrm{~km}$ (Fig. 15c). In the analysis mode, the location of the precipitation is correct but the amount is too small (Fig. 15d).

From these four episodes of heavy precipitation, it can be seen that the precipitation in both the operational forecast and analysis modes of the SM are reasonably good at the scale of the Ticino at Miorina catchment. However, the operational forecast shows a clear tendency to overestimate the rainfall amount, especially with heavy precipitation peaks. This overestimation is produced by the grid scale fraction of the precipitation, not by the cumulus convection scheme. The SM develops unrealistic rainstorms at one or a few grid points where it over-reacts to the condition of the atmosphere. The analysis, on the other hand, sometimes underestimates the precipitation amount slightly.

The location of the rainfall depends on the wind field, which in turn is influenced heavily by the boundary values of the driving model. The analysis boundary fields are of better quality and hence are expected to give better results for the analysis mode than the forecast. However, this is not always true. There are a few cases where the positioning of the forecast mode is more accurate, as at the end of the first episode. This is due presumably to the 1-hour interval in the forecast mode as opposed to the 6-hour interval in the 


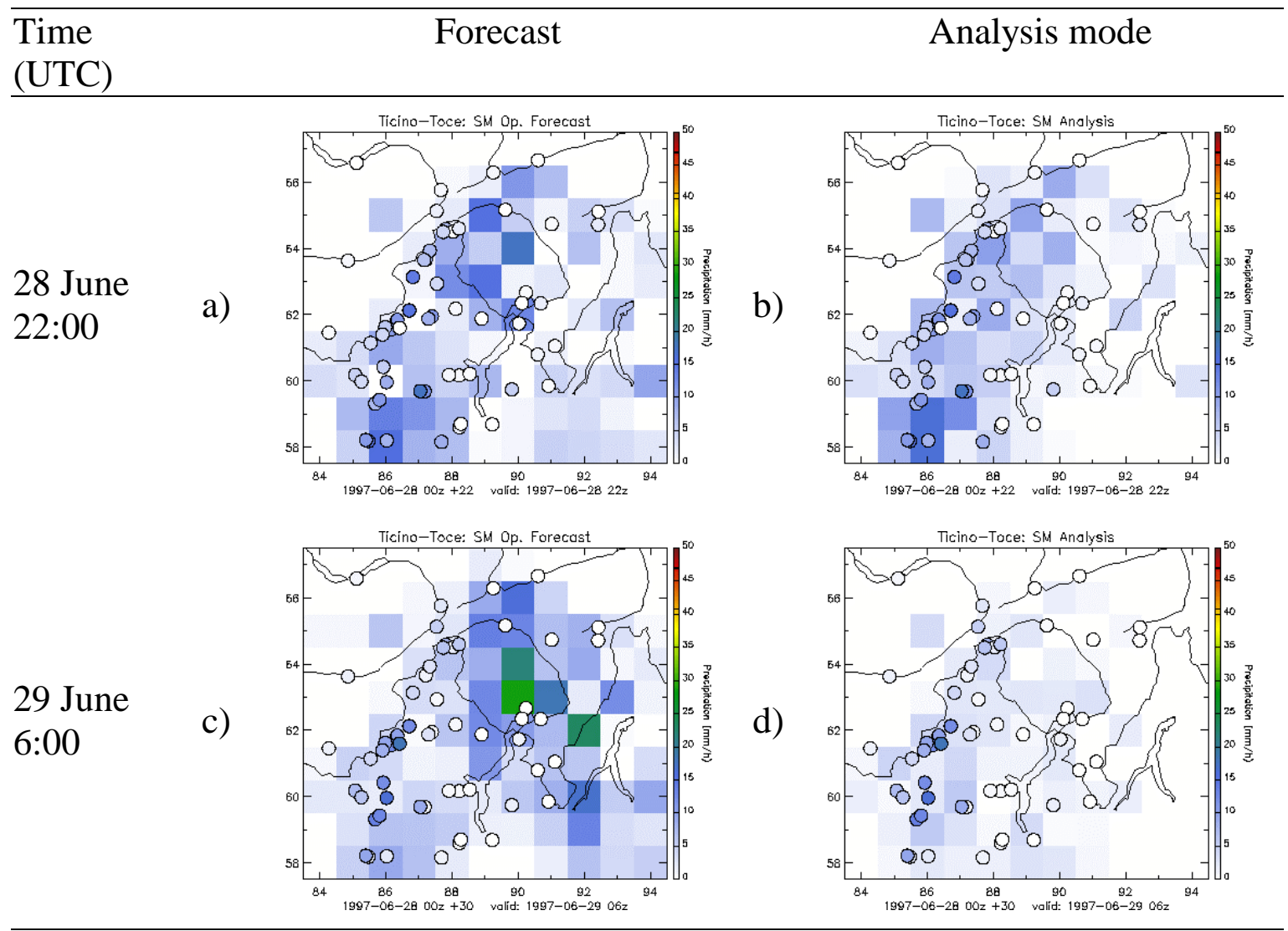

Fig. 15. Spatial distribution of 1-h precipitation at 28 June 1997 22:00 (a, b) and 29 June 6:00 UTC (c, d).

Left panels $(a, c)$ : SM forecast, right panels (b, d): SM analysis mode. Filled circles: 1-h observations.

boundary values in the analysis mode. This shows that not only the quality but also the frequency of the update of the boundary values is important.

Due to the large variations in the rainfall between adjacent grid cells, the catchment average precipitation is sensitive to the exact location of the rainfall. This is already visible in the case of the relatively large Ticino at the Miorina catchment. The error in average precipitation due to positioning errors grows with decreasing size of the catchment.

\section{VERTICAL RESOLUTION AND ADVECTION SCHEME}

Sensitivity analyses of the participating models were a major objective of the RAPHAEL project. Two sensitivity studies were conducted with the SM. The first study was related to the precipitation parameterisation, the vertical resolution of the model and the advection scheme. Because the precipitation parameterisation with cloud ice as an additional prognostic variable was never activated in the operational version of the SM, and its benefit was negligible for the selected episodes, these results are not presented here. Stein et al. (2000) found a significant impact for a $2.5 \mathrm{~km}$ grid but only minor effects for a $10 \mathrm{~km}$ grid, so that the grid size of the SM (14 km) is probably too large for the advection of cloud ice to have a significant effect.

The second sensitivity study was related to the evapotranspiration at the top of the soil model. It turned out that the evapotranspiration is not an important factor for the RAPHAEL heavy precipitation events. This is due to the advection of amounts of high humidity from the Mediterranean Sea towards the south slope of the Alps. Hence, the RAPHAEL episodes are not well suited to measure the influence of surface parameterisation.

\section{Vertical resolution}

The operational forecast mode of the SM used 20 vertical levels and a semi-Lagrangian advection scheme except for the last period of operation (September 1999 - July 2001), when the advection scheme was Eulerian and the number of vertical levels was increased from 20 to 31 . The semi- 
Lagrangian advection scheme is less accurate than the Eulerian, but allows a larger time step (240 s instead of $90 \mathrm{~s}$ ) and thus saves computing time, a critical issue for an operational model. The Eulerian advection scheme allows the application of a radiative upper boundary condition (Herzog, 1995) as opposed to the reflective upper boundary in the semi-Lagrangian version. This allows vertically propagating waves to leave the model domain and thus to avoid spurious noise caused by reflection. In consequence, the vertical nesting of the upper levels in the semiLagrangian model is no longer needed in the Eulerian version.

A set-up of the SM with 40 levels vertical resolution and an Eulerian advection scheme (E40L) has been tested against the operational forecast with 20 levels and semi-Lagrangian advection. The average precipitation was obtained in the same way as in the standard mode simulations.

To determine which of the two model changes (i.e. from the semi-Lagrangian 20 level forecast to the E40L version) accounts for the changes in precipitation, an SM version with 20 levels as for the operational forecast but with an Eulerian advection scheme (E20L) was used.

The first RAPHAEL episode shows the biggest response to the model changes. The two 20 -level versions give very similar results (Figure 16a). The first two SM runs within this episode also show equal behaviour for the E40L version. At the beginning of the third run, however, the E40L version produces two extreme peaks that were not present in the corresponding run of the operational forecast. These peaks consist mostly of grid scale precipitation, not convection. In turn, the E20L version has later, at 24 September 8:00 UTC, a higher peak than all other versions.

When the SM precipitation is compared with the observations at the time of the extreme peak on 23 September 20:00 - 23:00 UTC (only the operational forecast is shown in Fig. 12c), it is obvious that the amount of precipitation is clearly too high for all forecast versions. The exact occurrence of the peak in time and space differs little from version to version. It seems that the meteorological conditions around that time are such that all model versions (except the analysis mode, see above) overestimated the peak rainfall heavily.

There is little difference between the versions during the second episode (not shown). It is noteworthy that the convective fraction becomes smaller with increased vertical resolution. This effect is compensated for by an increased grid scale rainfall.

In the third episode, the difference between the operational forecast and E20L is usually small and of varying sign (Fig. 17a). A large increase occurs when changing the number of levels from the E20L to the E40L version (Fig. 17b).

Similar results are obtained for the fourth episode (not shown). The E20L and the operational version agree well but have considerably less precipitation than the E40L version. A comparison with observations shows that the rainfall peak is overestimated grossly in the version with 40 levels (not shown) although the precipitation pattern is more coherent and better positioned than in the 20 level versions, regardless of the advection scheme.

In general, the E40L version of the SM predicts considerably more precipitation during heavy precipitation events than the operational forecast. Interestingly, the convective precipitation has the opposite tendency to that of total precipitation, being slightly reduced in the 40-level version. The major difference in rainfall occurs when changing the vertical resolution of the model from 20 levels
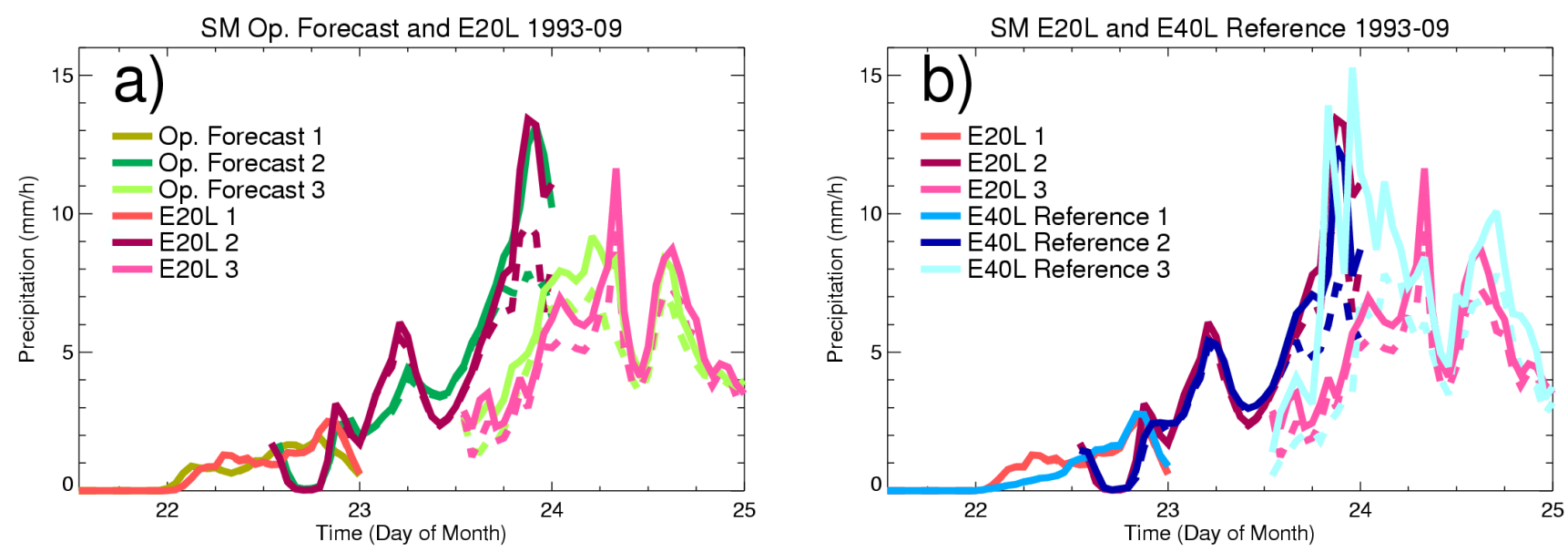

Fig. 16. Average precipitation during the Brig case over the Ticino at Miorina catchment. (a) operational forecast and E20L model version; (b) E20L and E40L model versions. 
to 40 levels. This is due presumably to the narrower vertical grid spacing in the 40 level versions. The saturation of a grid element is reached earlier with smaller grid cells.

The changes in the model set-up between the operational forecast, the E20L and the E40L versions of the SM affect only numerical aspects; there is no change in the model physics involved. This demonstrates that there can be a relatively large variation in the simulated rainfall due to purely numerical changes in the model.

\section{Conclusions}

The general conclusions that can be drawn from the verification 1993-2001 are discussed first, followed by some more specific conclusions pertaining to heavy precipitation events as drawn from the RAPHAEL case studies. While the general findings are also valid for the RAPHAEL cases, the opposite is not automatically true. Hence, the results of the sensitivity experiments cannot be assumed to show general behaviour of the model.

The mostly convective nature of the precipitation in summer makes it difficult to forecast accurately. In summer, the SM precipitation peak is too early in the afternoon and too strong, and then recedes too quickly. Model spin-up effects produce, on average, heavy precipitation at the start of the simulation and a sharp drop-off in the first few hours, especially at low elevations. The precipitation amount in the mountains in summer is overestimated considerably due to the too strong convection, as seen in the daily cycle of the grid points above $1500 \mathrm{~m}$ and in the seasonal totals.

In winter, the SM performs better. The general volume of precipitation is quite good. There is no diurnal forcing of the precipitation, and the diurnal cycles that appear in some winters are caused arbitrarily by fronts that pass coincidentally at the same time of day. The chessboard-like precipitation patterns are linked strongly to the orography and indicate that the model is too sensitive to sloping topography.

There is much variation and no clear trend in the scores for 1994-2001, except for the frequency bias in summer (threshold $0.1 \mathrm{~mm}$ ) that is decreasing with time. The winter $2000 / 2001$ rates the worst and 1995/1996 the second worst of all winters in all other scores. Both of these winters have little precipitation in the north-east but more than average precipitation in the north-west and on the south side of the Alps. This pattern is typical of Föhn cases. This could be an indication that the occurrence of Föhn cases reduces model performance, while the generally wet winter 1994/1995 clearly rates best in the probability of detection and the false alarm rate.

The following conclusions summarise the findings of the case studies and are restricted to events that are similar to those examined here, namely heavy precipitation events on the south-facing slopes of the Alps with strong advection of humidity from the south towards the Alps.

The Swiss Model provides adequate precipitation forecasts for flood prediction and warning purposes for catchments larger than approximately $2000 \mathrm{~km}^{2}$. For smaller areas, the precipitation within the catchment area is too sensitive to positioning errors of the model precipitation.

The Swiss Model overestimates the orographic effect over the south-facing slopes of the Alps. The overestimation occurs in the grid scale part of the precipitation, not in the convective parameterisation. Interestingly, the analysis mode tends, in general, to underestimate precipitation, especially when boundary values are available from the analysis of
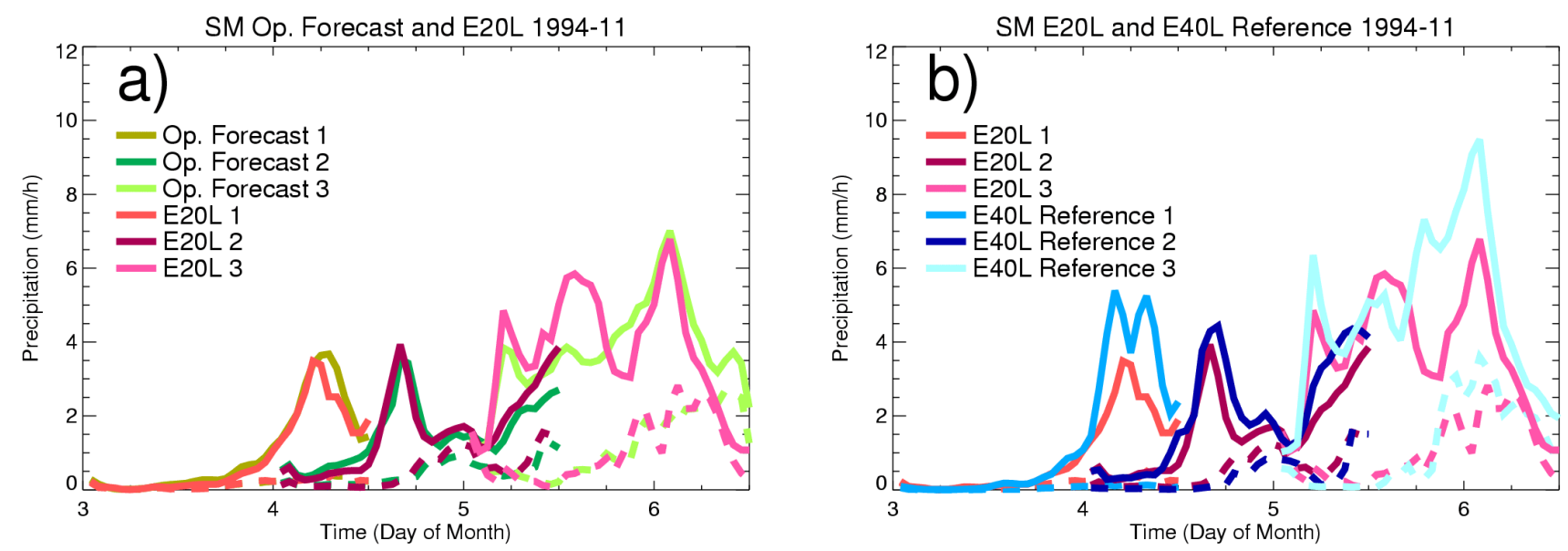

Fig. 17. As in Figure 16 but for the Piemonte case. 
the driving model. This is a hint that the overestimation could be caused at least partially by the boundary fields, despite the large distance of the studied area from the model boundary.

A frequent update of boundary values as in the operational forecast mode has a positive effect on the accuracy of the forecast, especially on the positioning of the rain. The low frequency of the six-hourly boundary-value updates in the analysis mode has a negative impact. Positioning errors in the rainfall occur in the latter due to the linear interpolation of the boundary fields between the times of the boundary value updates. Non-linear features such as fronts are not represented well enough between the six-hourly updates.

The vertical resolution of the Swiss Model has an unexpectedly large effect on the precipitation forecast. An increase in vertical resolution produces a pronounced increase in the already overestimated precipitation amounts during heavy precipitation.

It is not possible to decide whether the Eulerian or the semi-Lagrangian version of the model is more accurate. The differences between the two advection schemes are small and of varying sign. The Eulerian version, however, gives more coherent precipitation patterns.

\section{Outlook}

In the general tendency in numerical weather prediction towards non-hydrostatic models with higher resolution, research models (e.g. Stein et al., 2000; Mass et al., 2002) lead the operational model by several years. Before a research version of a model can become operational, the expected improvement in the quality has to outweigh an eventual computing performance penalty. The verification of precipitation is an important part of this quality assessment. As it is usually not possible to evaluate a potential new operational model version for more than a few months or sometimes even less, the evaluation of specific cases as presented for the RAPHAEL study is important to gain insight into the model behaviour during extreme events.

The SM was replaced as operational model in spring 2001 by the Alpine Model (aLMo), the Swiss configuration of the Local Model (LM; Doms and Schättler, 2002) developed by the Consortium for Small Scale Modelling (COSMO, see www.cosmo-model.org). The aLMo is a non-hydrostatic model with $7 \mathrm{~km}$ mesh size horizontally and 45 layers in the vertical. An increased resolution however does not lead automatically to better scores but may increase the realism of the structures (Stein et al., 2000; Mass et al., 2002). It would be worthwhile to redo the RAPHAEL case studies with aLMo to document the improvement by the higher resolution for extreme events.

At the beginning of the daily operations of aLMo, an unrealistically large grid cell to grid cell variability in precipitation fields was a major concern for the forecasters. Sensitivity studies with the aLMo showed that this could be reduced considerably by filtering the orography, reducing the horizontal diffusion in steep topography and the introduction of 3D-transport of precipitation (Gassmann, 2002). The Swiss operational aLMo now uses filtered orography and a modified horizontal diffusion depending on the underlying orography to reduce the variability in precipitation fields. The overall amount of precipitation has not changed throughout these modifications. The prognostic precipitation scheme is currently still being investigated.

The spin-up effect in precipitation reported here for the SM no longer occurs in the aLMo. While the SM started from an interpolated analysis of the coarser driving model, the aLMo now uses as initial fields its own analysis derived on the same grid. The analysis scheme used in aLMo is the nudging technique. The development here goes towards the inclusion of non-conventional data such as radar data, Global Positioning System (GPS)-derived atmospheric water content and satellite-derived data.

\section{Acknowledgments}

The case studies were funded as EU-project No. ENV4CT97-0552 (project RAPHAEL) by the Swiss Federal Office for Education and Science (BBW), grant No. 97.0069-1. The authors acknowledge the support of Jean Quiby, Head of Process Models at MeteoSwiss and all coworkers.

\section{References}

Arakawa, A. and Schubert, W.H., 1974. Interaction of a cumulus cloud ensemble with the large-scale environment. Part I. $J$. Atmos. Sci., 31, 674-701.

Benoit, R., Schär, C., Binder, P., Chamberland, S., Davies, H. C., Desgagné, M., Girard, C., Keil, C., Kouwen, N., Lüthi, D., Maric, D., Müller, E., Pellerin, P., Schmidli, J., Schubiger, F., Schwierz, C., Sprenger, M., Walser, A., Willemse, S., Yu, W. and Zala, E., 2002. The real-time ultrafinescale forecast support during the special observing period of the MAP. Bull. Amer. Meteorol. Soc., 83, 85-109.

Bougeault, P., Binder, P., Buzzi, A., Dirks, R., Houze, R., Kuettner, J., Smith, R.B., Steinacker, R. and Volkert, H., 2001: The MAP Special Observing Period. Bull. Am. Meteorol. Soc., 82, 433462.

Cherubini, T., Ghelli, A. and Lalaurette, F., 2002. Verification of precipitation forecasts over the Alpine region using a highdensity observing network. Weather Forecast., 17, 238-249.

Doms, G. and Schättler, U., 2002. A description of the nonhydrostatic regional model LM. Part I: Dynamics and numerics. Deutscher Wetterdienst (DWD), Offenbach (available at www.cosmo-model.org). 
Emanuel, K.A., 1991. A scheme for representing cumulus convection in large-scale models. J. Atmos. Sci., 48, 2313-2335.

Emanuel, K.A. and Zivkovic-Rothman, M., 1999. Development and evaluation of a convection scheme for use in climate models. J. Atmos. Sci., 56, 1766-1782

Frei, C. and Schär, C., 1998. A precipitation climatology of the alps from high-resolution rain-gauge observations. Int. $J$. Climatol., 18, 873-900.

Gassmann, A., 2002. 3d-transport of precipitation. In : COSMO Newsletter No. 2, G. Doms and U. Schättler (Eds.), Deutscher Wetterdienst, Offenbach, Germany. Available on-line at www.cosmo-model.org.

Grell, G.A., 1993. Prognostic Evaluation of Assumptions Used by Cumulus Parameterizations. Mon. Weather Rev., 121, 764787

Herzog, H.-J., 1995. Testing a radiative upper boundary condition in a nonlinear model with hybrid vertical coordinate. Meteorol. Atmos. Phys., 55, 185-204.

Jasper, K. and Kaufmann, P., 2002. Coupled runoff simulations as validation tool for atmospheric models at the regional scale. Quart. J. Roy. Meteorol. Soc., 129, 673-692.

Jasper, K., Gurtz, J. and Lang, H., 2002. Advanced flood forecasting in Alpine watersheds by coupling meteorological observations and forecast with a distributed hydrological model. J. Hydrol., 267, 40-52.

Kaufmann, P., 2002. Swiss Model simulations for extreme rainfall events on the south side of the Alps. Arbeitsberichte MeteoSchweiz, 198, MeteoSwiss, Zurich, Switzerland.
Majewski, D., 1991. The Europa Modell of the Deutscher Wetterdienst. Proc. ECMWF Seminar on numerical methods in atmospheric models, Vol II, September 1991, 147-191.

Mass, C.F., Ovens, D., Westrick, K. and Colle, B.A., 2002. Does increasing horizontal resolution produce more skillful forecasts? Bull. Amer. Meteorol. Soc., 83, 407-430.

Mladek R., Barckicke, J., Binder, P., Bougeault, P., Brzovic, N., Frei, C., Geleyn, J. F., Hoffman, J., Ott, W., Paccagnella, T., Patruno, P., Pottier, P. and Rossa, A., 2000. Intercomparison and evaluation of precipitation forecasts for MAP seasons 1995 and 1996. Meteorol. Atmos. Phys., 72, 111-129.

Müller, E., Frühwald, D., Jackobsen, I., Link, A., Majewski, D., Schwirner, J.-U. and Wacker, U., 1987. Results and prospects of mesoscale modelling at the Deutscher Wetterdienst. In: Shortand Medium-Range Numerical Weather Prediction, T. Matsuno (Ed.), Collection of papers presented at the WMO/IUGG NWP symposium, Tokyo, 4-8 August 1986, 533-546.

Stein, J., Richard, E., Lafore, J. P., Pinty, J. P., Asencio, N. and Cosma, S., 2000. High-resolution non-hydrostatic simulations of flash-flood episodes with grid nesting and ice-phase parameterization. Meteorol. Atmos. Phys., 72, 203-221.

Tiedtke, M., 1989. A comprehensive mass flux scheme for cumulus parameterization in large-scale models. Mon. Weather Rev., 117, $1779-1800$.

Volkert H., 2000: Heavy Precipitation in the Alpine Region (HERA): Areal rainfall determination for flood warnings through in-situ measurements, remote sensing and atmospheric modelling. Meteorol. Atmos. Phys., 72, 73-85. 